\title{
Las escrituras epicóricas de la Península Ibérica
}

\author{
The epichoric scripts of the \\ Iberian Peninsula
}

\author{
Joan Ferrer i Jané \\ Universitat de Barcelona / \\ LITTERA Group \\ joan.ferrer.i.jane@gmail.com
}

Resumen: Las escrituras epicóricas de la península ibérica pueden agruparse por sus características internas en dos grandes grupos: las escrituras septentrionales, casi completamente descifradas, y las meridionales, que presentan aún muchos signos sin valores de consenso. El primer grupo está compuesto por la escritura ibérica nororiental y por la escritura celtibérica y el segundo, por la escritura ibérica suroriental y la escritura del sudoeste. No obstante, todo apunta a la existencia de otras escrituras meridionales aun por categorizar entre las que destacan la escritura de Espanca y un pequeño conjunto localizado principalmente en el Valle del Guadalquivir que empezamos a identificar bajo la denominación de turdetano. Ambas familias comparten un antecesor común, que a su vez deriva probablemente del alfabeto fenicio, y que justificaría las características comunes: un corpus similar de signos, la coexistencia de signos alfabéticos y silábicos y el mecanismo de las dualidades para representar sonidos similares mediante marcas añadidas a un mismo signo base.

Palabras clave: Escrituras paleohispánicas. Inscripciones paleohispánicas. Escritura ibérica.

Escritura celtibérica. Escritura del sudoeste. Abecedarios. Genealogía de las escrituras.

Abstract: The epichoric scripts of the Iberian Peninsula can be grouped by their internal characteristics in two large groups: the northern scripts, almost completely deciphered, and the southern ones, which still have many signs without consensus values. The first group is made up of the north-eastern Iberian script and of the Celtiberian script. The second group basically includes the south-eastern Iberian script and the south-western script. However, everything points to the existence of other southern scripts still to be categorized. Among them are The Espanca script and a small group, located mainly in the Guadalquivir Valley that we are already beginning to identify under the denomination of Turdetanian. Both families share a common ancestor, which would probably stem from the Phoenician alphabet, and that would justify the common characteristics of the two families: a similar corpus of signs, the coexistence of alphabetical and syllabic signs and the use of dualities to represent similar sounds by means of adding marks to the same base sign.

Keywords: Palaeohispanic scripts. Palaeohispanic inscriptions. Iberian script. Celtiberian script. Southwestern script. Abecedaries. Script genealogy.

Recepción: 21.01.2020 | Aceptación: 04.04.2020

Financiación: Este trabajo se enmarca en el proyecto FFI2015-63981-C3-1-P "Hesperia: lenguas, epigrafía y onomástica paleohispánica”. 


\section{Introducción}

Las escrituras epicóricas de la península ibérica pueden agruparse por sus características internas en dos grandes grupos: las escrituras nororientales y las meridionales.

El grupo nororiental está compuesto por la escritura ibérica nororiental, usada para representar la lengua ibérica, y por la escritura celtibérica, usada para representar la lengua celtibérica, aunque cada una de ellas con múltiples variantes. Adicionalmente, algunas inscripciones nororientales, especialmente las localizadas en el territorio histórico de los vascones, no pueden ser clasificadas claramente como ibéricas ni como celtibéricas.

El grupo meridional comprende la escritura ibérica suroriental, usada para representar la lengua ibérica, y la escritura del sudoeste o tartésica, usada para una lengua desconocida con la misma denominación. No obstante, el abecedario de Espanca no encaja bien con ninguna de las dos anteriores y probablemente también debería ser categorizada como escritura distinta. Esta circunstancia apunta a la existencia de otras escrituras meridionales entre el grupo de inscripciones meridionales que no admiten una clasificación clara entre las ya identificadas. Entre ellas destacan un pequeño conjunto que se localiza principalmente en el bajo y medio Valle del Guadalquivir y que presentan características comunes. Estas inscripciones estarían representando la lengua característica de esta zona, tal como documentan la antroponimia y la toponimia, y que denominamos turdetana.

En el mapa de la fig. 1 se representan las áreas de dispersión de las escrituras epicóricas paleohispánicas y el alfabeto greco-ibérico, usado para representar la lengua ibérica. El área a lo largo de la costa sur de la península ibérica y las Islas Baleares corresponde a la zona donde la cultura escrita predominante fue la fenicia y donde no se usaron las escrituras paleohispánicas o donde los hallazgos son residuales. 


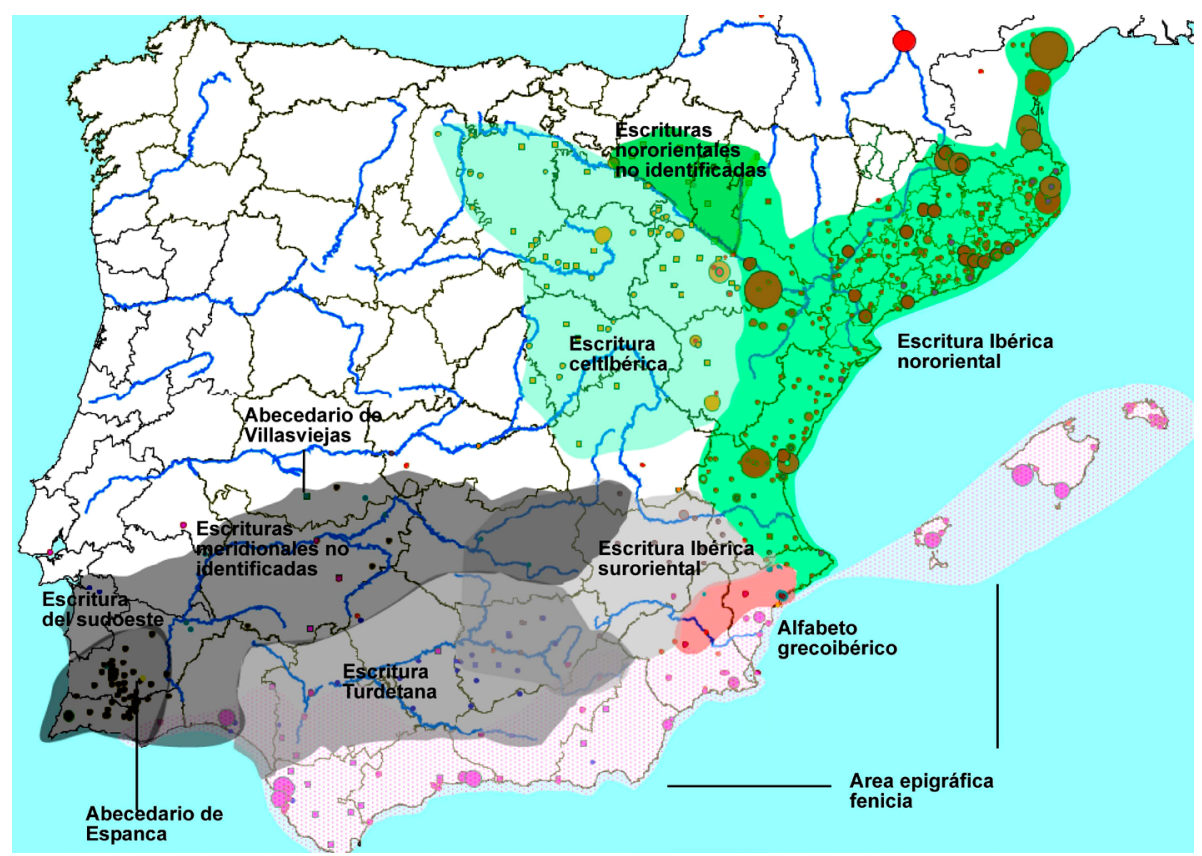

Fig. 1. Mapa de distribución de las escrituras paleohispánicas.

\subsection{Características generales}

Todos los sistemas de escritura epicóricos paleohispánicos se caracterizan por un corpus similar de signos y la coexistencia de signos alfabéticos y silábicos: los primeros se usaron para vocales y consonantes continuas y los segundos para las oclusivas. Este componente silábico implica algunas limitaciones en la notación de las lenguas paleohispánicas, como la imposibilidad de escribir un grupo de consonantes oclusiva + continua o una oclusiva al final de palabra.

Los primeros intentos de descifrar las escrituras de paleohispánicas se remontan al siglo XVI, pero el mayor logro no se produjo hasta principios del siglo XX, cuando Manuel Gómez-Moreno (1922; 1925; 1949) encontró la clave del desciframiento de la escritura ibérica nororiental al identificar el carácter silábico de los signos para las oclusivas, mientras que el resto de los signos mantenían su valor alfabético: vocálico o consonántico. La decodificación fue esencialmente posible gracias a la existencia de inscripciones monetales, que en algunos casos eran bilingües y, en otros casos, claramente vinculables a lugares conocidos a través de fuentes antiguas griegas y latinas. 
Fue de gran ayuda el hallazgo de la lámina de plomo de La Serreta d'Alcoi $\left(\mathrm{BDH}^{1}\right.$ A.04.01) de lengua ibérica, pero escrita en el alfabeto greco-ibérico, que reveló la fonética de la lengua ibérica. También fue útil el hallazgo de una inscripción latina con una extensa relación de antropónimos ibéricos, conocida como Turma Salluitana (CIL I $\left.{ }^{2} 709\right)$ que permitió verificar que la nueva propuesta era correcta.

En cambio, el desciframiento de las escrituras meridionales se encuentra mucho menos desarrollado, principalmente debido al escaso número de inscripciones conocido, y aun hoy en día existen divergencias notables entre los investigadores principales.

A pesar de que consideramos la escritura ibérica nororiental en términos generales descifrada, algunos aspectos de esta escritura no se descifraron completamente hasta fechas muy recientes. Es el caso de la existencia y alcance del sistema dual, algunos aspectos concretos del cual aún se están investigando y siguen sin estar completamente claros.

El sistema dual es un mecanismo compartido por la mayoría de las escrituras epicóricas paleohispánicas que permite reaprovechar signos para representar valores fonéticos cercanos mediante el añadido de un trazo adicional al signo base (Maluquer 1968; De Hoz 1985; Correa 1992a; Ferrer 2005; 2010a; 2015; Jordán 2005; 2007). En lugar de ser un simple diacrítico, este trazo tiende a ser parte del signo en sí mismo y, por lo tanto, no siempre es fácil aislarlo a primera vista. El reciente descubrimiento de abecedarios duales confirma que estas dualidades se integraron en los abecedarios estándar (figs. 8 y 10), donde el par de signos formando dualidad aparece siempre en el mismo orden: la variante compleja, con su trazo adicional, en primer lugar $\mathrm{y}$, posteriormente, la variante simple.

Estas dualidades pueden afectar a diferentes conjuntos de sonidos: oclusivas, consonantes continuas e incluso vocales. Sin embargo, a pesar de su aparición en los abecedarios, solo para las oclusivas se ha confirmado la oposición fonética (en este caso, sordas y sonoras) entre la variante simple y la compleja. Así, pues, de acuerdo con la extensión del uso de dualidades, es posible identificar diferentes subconjuntos dentro de cada escritura (fig. 2):

- La escritura ibérica nororiental se puede dividir en: dual ampliada, cuando las dualidades afectan a las oclusivas, consonantes continuas y voca-

1 Las inscripciones se identifican con el código de la base de datos Hesperia:

$<$ http://hesperia.ucm.es $>$. 
les, compuesta de 46 signos; dual estándar, cuando solo afecta a las oclusivas, compuesta de 39 signos, y no-dual, cuando la escritura carece de dualidades, compuesta solo de 29 signos.

- La escritura celtibérica, ya sea en su variante oriental u occidental, se puede dividir en dual estándar, compuesta de 36 signos, y no-dual, compuesta de 26 signos.

- La escritura ibérica suroriental, con más de 40 signos, de acuerdo con la documentación disponible en la actualidad, parece ser siempre dual, con dualidades tanto para las oclusivas como para las consonantes continuas, pero no para las vocales.

- La escritura del sudoeste, con más de 30 signos, y la escritura representada por el abecedario de Espanca, de 27 signos, son claramente no duales.

- La escritura turdetana presenta sólidos indicios de disponer también de un sistema dual de tipo meridional, sin dualidades para las vocales, pero sí para las oclusivas, incluyendo labiales, y para gran parte de las consonantes continuas, incluyendo a la lateral.

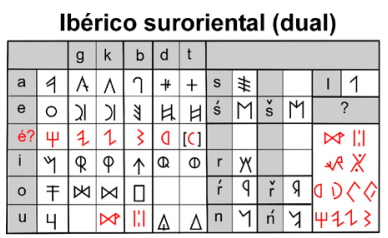

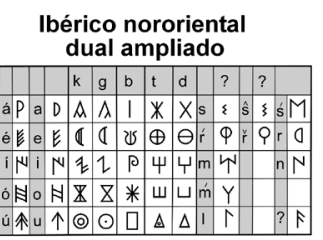

Celtibérico occidental

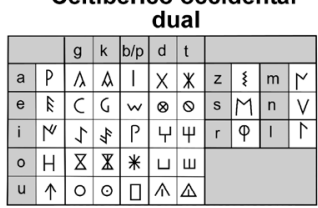

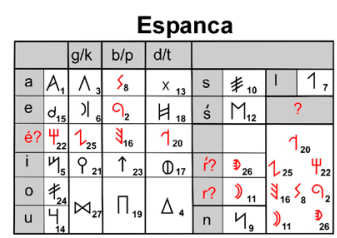

$$
\begin{gathered}
\text { Ibérico nororiental } \\
\text { dual estándar }
\end{gathered}
$$

\begin{tabular}{|c|c|c|c|c|c|c|c|c|c|c|}
\hline & & & & & & & \\
\hline & & $k$ & $\mathrm{~g}$ & b & $\mathrm{t}$ & d & & & & \\
\hline$a$ & $P$ & $\Delta \lambda$ & $\lambda$ & 1 & $x$ & $x$ & $\mathrm{~s}$ & $\xi$ & ś & $M$ \\
\hline e & $E$ & $\mathbb{C}$ & C & ४ & $\oplus$ & $\theta$ & r & $\phi$ & - & D \\
\hline 1 & N & $y^{2}$ & 5 & $p$ & $\Psi$ & 4 & m & $T$ & $n$ & $\Gamma$ \\
\hline 0 & $\mathrm{H}$ & $\mathbb{Z}$ & Z & * & ш & ш & '́ & V & ? & I \\
\hline & $\uparrow$ & 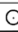 & 0 & 目 & $\Delta$ & $\Delta$ & I & $\Gamma$ & & \\
\hline
\end{tabular}

Celtibérico oriental

\begin{tabular}{|c|c|c|c|c|c|c|c|c|c|c|}
\hline & & \multicolumn{9}{|c|}{ dual } \\
\hline & & $g$ & $k$ & $b / p$ & $d$ & $t$ & & & & \\
\hline a & $P$ & $\lambda$ & $\Delta$ & 1 & $x$ & * & $z$ & $\xi$ & $\mathrm{m}$ & $T^{2}$ \\
\hline e & $E$ & C & G & 3 & $\otimes$ & $\theta$ & s & $M$ & $n$ & r \\
\hline $\mathrm{i}$ & $N$ & 5 & $f$ & $p$ & ५ & 4 & r & $\phi$ & 1 & $\Gamma$ \\
\hline 0 & $\mathrm{H}$ & 8 & $\mathbb{Z}$ & * & $\sqcup$ & ш & & & & \\
\hline$u$ & $\uparrow$ & 0 & $\odot$ & ( & $\Delta$ & $\Delta$ & & & & \\
\hline
\end{tabular}
dual
Celtibérico occidental

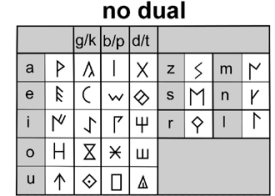

\begin{tabular}{|c|c|c|c|c|c|c|c|c|}
\hline & & $?$ & G/k & bl & & & & \\
\hline$a$ & A & s & $\Lambda$ & \} & $x$ & $s$ & 丰 & 1 \\
\hline e & 0 & & ) & 0 & H & ś & $M$ & ? \\
\hline $\mathrm{i}$ & 4 & & $\phi$ &.$\uparrow$ & (1) & i & $r$ & IYO \\
\hline 0 & $\neq$ & & 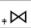 & , & $+A$ & $r$ & 9 & $V \Psi \mathcal{H}$ \\
\hline$u$ & 4 & 4 & $\left.{ }_{4}\right)$ & 仴 & ${ }_{4} \Delta$ & $n$ & 4 & $8 \& 1$ \\
\hline
\end{tabular}

Sudoeste

Ibérico nororiental

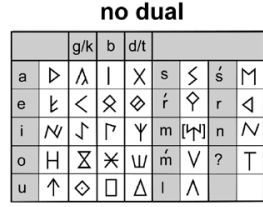

Celtibérico oriental no dual

Fig. 2. Escrituras paleohispánicas epicóricas.

Cuadro comparativo general. 
Si bien los sistemas duales estándar de la escritura ibérica nororiental y de la escritura celtibérica son aceptados mayoritariamente, las dualidades ampliadas del ibérico nororiental y el sistema dual para el ibérico sudoriental y el reciente sistema dual turdetano todavía son controvertidos. Algunos estudiosos consideran que no habría oposición fonética y explican la diversidad de signos como un mero resultado de la variación normal de una escritura manual (De Hoz 2013, 655, n. 27).

\subsection{Orígenes, evolución y desaparición}

\subsubsection{El modelo genealógico}

Se acepta unánimemente que las escrituras paleohispánicas tienen un ancestro común, que en última instancia provendría únicamente de la escritura fenicia (De Hoz 1985, 445; 2010, 488, 624; Correa 1987, 275; 2005, 137; Rodríguez Ramos 2004, 41; Valério 2008, 114). No obstante, algunos autores consideran posible cierta influencia del alfabeto griego ( $M L H$ III, 135-136; Adiego 1993, 22; Correia 1996, 21).

Por otro lado, no hay consenso sobre cómo se podrían haber creado las diferentes escrituras paleohispánicas y establecer su dependencia mutua (fig. 3). Una de las principales preguntas sin resolver es cuál es la relación genealógica entre las dos escrituras ibéricas: a pesar de que ambas se usan para la misma lengua, las diferencias internas entre ellas son tan sorprendentes que es difícil sostener que una simplemente surja de la otra.

El modelo teórico más simplificado (fig. 3.A) es el propuesto por Rodríguez Ramos (2004; 2005), quien considera a la escritura del sudoeste como la escritura paleohispánica original y asume una cadena de derivación directa desde la supuesta escritura más antigua hasta la más reciente: es decir, sudoeste $\rightarrow$ Ibérico suroriental $\rightarrow$ Ibérico nororiental $\rightarrow$ Celtibérico. Otro modelo (fig. 3.B) es el defendido por Correa (1985; 1992a; 1993; 1996; 2005; 2009), que combina, con algunas variaciones menores, los modelos alternativos propuestos por De Hoz (1986a; 1993a; 1993b; 1996; 2005a; 2010; 2011) y por Rodríguez Ramos $(2004 ; 2005)$. Esta propuesta considera que la escritura original paleohispánica es la tartésica, creada en la zona nuclear tartésica (Cádiz, Sevilla y Huelva) durante el siglo VII a. C. y que estaría representada por algunas de las inscripciones meridionales de clasificación dudosa. Y que de ella derivarían la escritura del sudoeste y la ibérica suroriental y de esta última la ibérica nororiental; y, a continuación, la celtibérica como en el primer modelo. Un tercer modelo (fig. 3.C) sería el propuesto por De Hoz (1993a; 
1993b; 1996; 2005; 2010; 2011), que introduce la posibilidad de que la escritura de Espanca fuera en realidad la escritura tartésica, es decir, la escritura paleohispánica original. Este modelo también considera la existencia de una escritura meridional no ibérica representada por algunas de las inscripciones meridionales de clasificación incierta. Esta escritura sería el ancestro común de las dos escrituras ibéricas, circunstancia que permitiría explicar mejor las diferencias entre ellas.
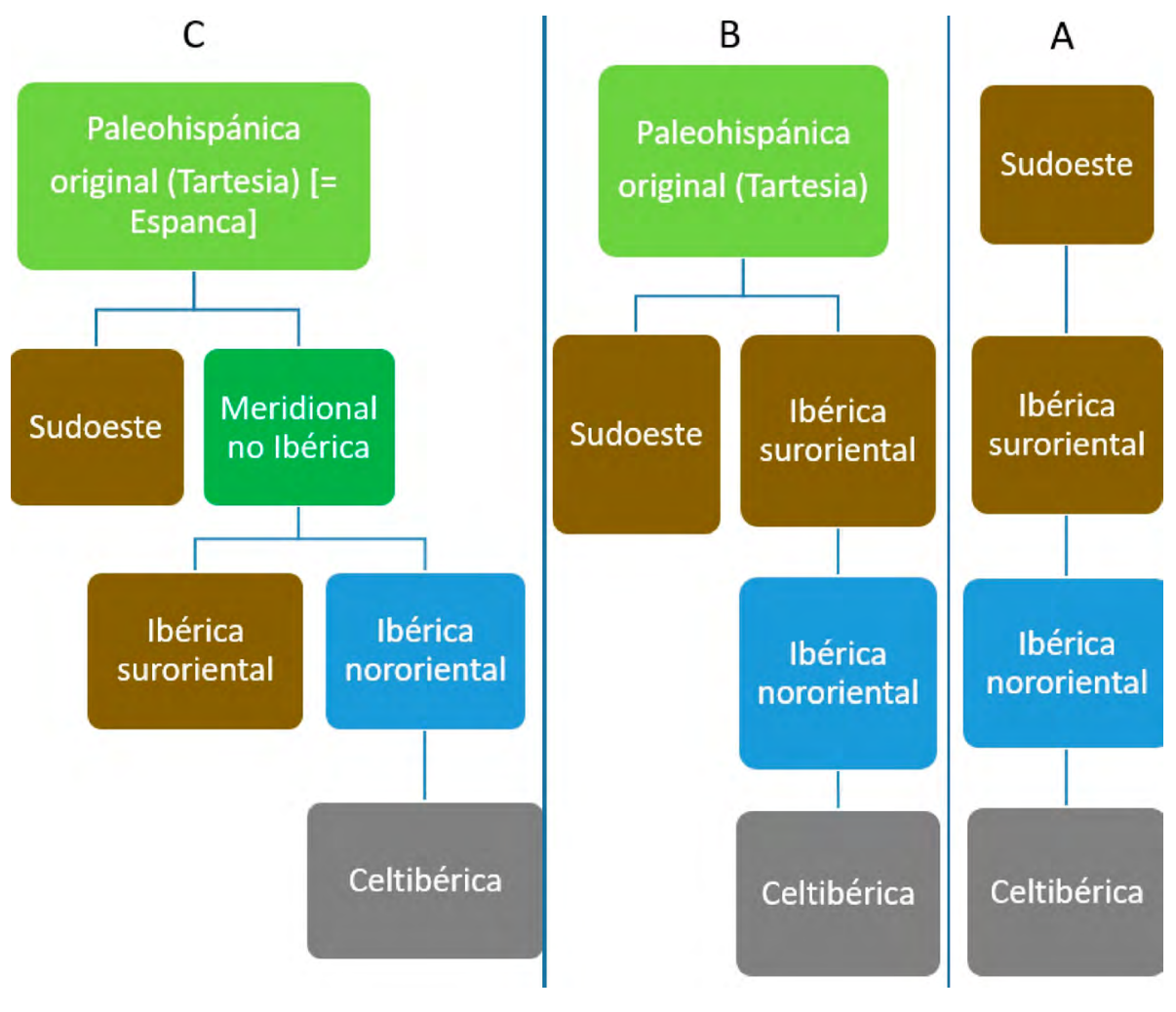

Fig. 3. Modelos propuestos de genealogía de las escrituras paleohispánicas: Rodríguez Ramos (A), Correa (B), De Hoz (C).

El modelo que he propuesto recientemente (fig. 4) trata de explicar de una manera diferente por qué hay una clara división entre las escrituras nororientales y las meridionales (Ferrer 2017a). Esta nueva propuesta considera la existencia de dos escrituras intermedias, la escritura paleohispánica meridional original y la escritura paleohispánica nororiental original, ambas derivadas de la escritura paleohispánica original, para explicar las caracterís- 
ticas internas comunes de ambos grupos junto con las diferencias entre ellas. Estas dos escrituras intermedias podrían ser escrituras aún no identificadas o coincidir con alguna de las ya conocidas con características adecuadas. Esta propuesta defiende que las afinidades y diferencias entre las formas y los valores de los signos de los dos grupos permiten la reconstrucción de una escritura original paleohispánica caracterizada por tener como máximo tres vocales; los correspondientes signos silábicos velar, dental y labial asociados a estas vocales; tres sibilantes, una vibrante y probablemente algunas otras series de signos silábicos, en un número suficiente para justificar el conjunto de signos paleohispánicos comunes. Además, la existencia de un sistema dual en las dos escrituras ibéricas sugiere que las dos escrituras intermedias deberían haber sido duales, y, por lo tanto, también lo debería haber sido su ancestro común, la escritura paleohispánica original.

Según esta propuesta, la escritura paleohispánica original podría haber sido creada en algún puerto peninsular bajo la influencia comercial fenicia y, más adelante, podría haberse adaptado dos veces independientemente para escribir dos idiomas diferentes con nuevos requisitos fonéticos, especialmente un inventario más amplio de vocales. Las vocales adicionales y sus signos silábicos correspondientes podrían haber sido creados entonces escogiendo entre los signos no adecuados de la escritura original, pero siguiendo diferentes criterios cada una de las dos escrituras intermedias, lo que finalmente explicaría las diferencias observadas entre las dos escrituras ibéricas. De acuerdo con esta propuesta, la escritura original meridional probablemente se creó para el idioma tartésico (turdetano) en algún puerto de la costa atlántica sur de la península ibérica, y posteriormente se podría haber adaptado al idioma ibérico en un punto del territorio ibérico del alto Guadalquivir. En cambio, la escritura original nororiental probablemente se creó específicamente para la lengua ibérica en algún puerto de la costa mediterránea del noreste de la península ibérica. 

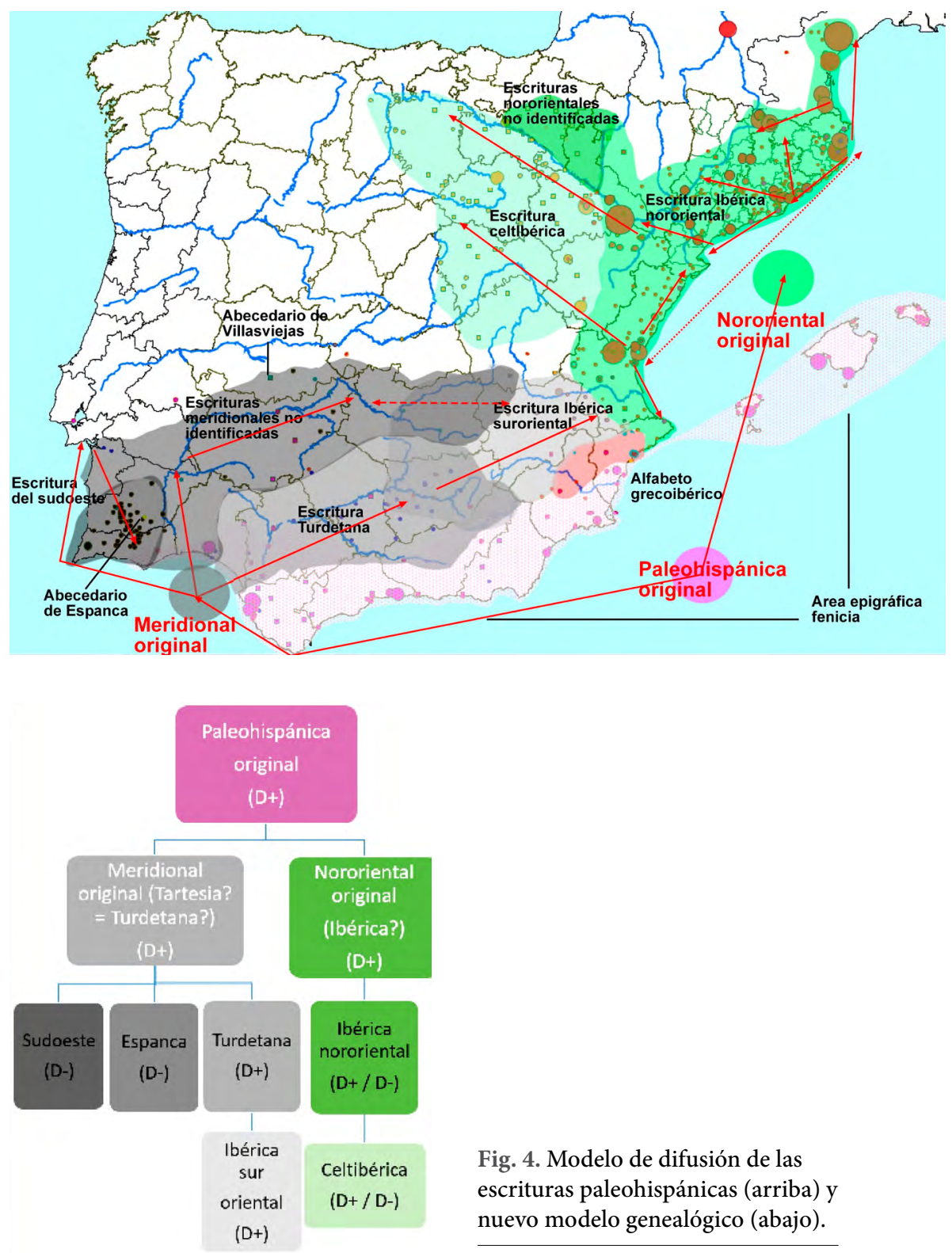

Fig. 4. Modelo de difusión de las escrituras paleohispánicas (arriba) y nuevo modelo genealógico (abajo).

\subsubsection{Primeros y últimos testimonios}

Las cronologías más antiguas normalmente aceptadas para la escritura del sudoeste se sitúan en el s. VII a. C. (De Hoz 2010, 516), aunque algunos la remontan al s. VIII a. C. (Correia 1996, 63). No obstante, las estelas del sudoeste con contextos arqueológicos conocidos son muy escasas y aún 
menos las que permiten una aproximación cronológica significativa (media docena) de forma que nada impediría situarlas en el s. VI a. C. (Rodríguez Ramos 2002b, 87; Valério 2016) o con una interpretación cronológicamente restrictiva de los mismos datos, incluso en el s. V a. C. ${ }^{2}$

De forma similar, la mayor parte de la docena de grafitos cerámicos atribuidos a la escritura tartésica son muy breves (De Hoz 2007, 30-32; Correa y Zamora 2008; Correa 2011; Toscano y Correa 2014) y la mayor parte de dudosa clasificación, hasta el punto de que algunos pueden pasar o han pasado por fenicios (Mederos y Ruiz 2001, 103) y algunos incluso, por simples decoraciones o marcas de alfarero. En muchos casos no es posible determinar ni tan siquiera si se trata de una escritura semisilábica o no, circunstancia que, de no confirmarse, los eliminaría al menos del tronco principal del árbol genealógico de las escrituras paleohispánicas. De hecho, la mayor parte son tan breves e incomprensibles que en el supuesto de que hubiera existido un uso local del alfabeto fenicio, o una ligera adaptación de este, para representar las lenguas locales, nos sería imposible distinguir unos de otros.

Por lo que respecta a las dos escrituras ibéricas, los testimonios más antiguos de la escritura ibérica suroriental solo se remontan al s. IV a. C. (De Hoz 1993a, 641; 2015, 394; Rodríguez Ramos 2004, 70; Correa 2009 281, n. 41), aunque también con problemas por disponer de un escaso número de ejemplares con cronologías seguras. En cambio, los testimonios más antiguos de la escritura ibérica nororiental se remontan a finales del s. V a. C. (De Hoz 1989, 542; Ferrer 2005, 967), teniendo en cuenta siempre la cronología más restrictiva posible en el intervalo establecido por el tipo de soporte y el contexto arqueológico, cuando está disponible (Ferrer et al. 2016).

La inscripción ibérica nororiental más antigua por tipología cerámica sería una copa-escifo de cerámica ática de figuras negras atribuida al estilo del pintor de Haimon que se podría llegar a datar en la primera mitad del siglo $\mathrm{V}$ a. C., y que estratigráficamente encajaría sin problemas en la segunda mitad del s. V a. C., puesto que apareció en el último estrato antes de la roca natural y por debajo de la muralla sudoeste del Puig de Sant Andreu de Ullastret (Ferrer 2005, 967). También puede datarse a finales del s. V a. C. una cerámica ática de barniz negro del Mas Castellar de Pontós que apareció en el derrumbe del

2 En esta línea cronológicamente restrictiva se encuentra la comunicación de Javier Jiménez Ávila en el coloquio de Loulé (23/10/2019): El contexto arqueológico de la epigrafía del Suroeste Peninsular. 
edificio singular que apareció por debajo de los niveles del oppidum del s. IV a. C. (Ferrer et al. 2016).

En cuanto a las inscripciones ibéricas surorientales, la de cronología más antigua es una inscripción sobre una vasija globular (BDH J.03.02) aparecida en la sepultura XII de la necrópolis de Estacar de Robarinas (Cástulo) que se sitúa en primera mitad del s. IV a. C. (García Gelabert y Blázquez 1988). Mientras que los plomos de La Bastida de les Alcuses (BDH V.17.02 y 05) deberían ser del tercer cuarto del s. IV a. C., momento que corresponde a la destrucción del poblado.

Respecto de la cronología de las inscripciones más antiguas, el nuevo modelo (fig. 4) presenta problemas similares a los modelos anteriores (fig. 3), puesto que, si realmente la escritura paleohispánica original se creó en el s. VII a. C. y en el mismo s. VII ya contásemos con ejemplos en la escritura del sudoeste, la escisión entre escrituras meridionales y nororientales se debería haber producido en el mismo s. VII a. C. En cambio, los primeros testimonios nororientales son del s. V a. C. No obstante, como se ha indicado, las cronologías supuestas para la escritura del sudoeste y tartésica se basan en un conjunto muy reducido de piezas, la mayoría de ellas de cronología y/o clasificación problemática. Los futuros hallazgos y las mejoras en las técnicas de datación determinarán si eso es así o no; pero tanto para los modelos actualmente planteados de genealogía de las escrituras paleohispánicas, como para el nuevo modelo, encajaría mejor una cronología algo más moderna para los hallazgos meridionales más antiguos y una cronología algo más antigua para los hallazgos nororientales más antiguos, quizás el s. VI a. C. sería un buen punto de encuentro.

Por lo que respecta a su desaparición, excepto en el caso de la escritura del sudoeste, que parece ya haber desaparecido en el mismo siglo V a. C., el resto de las escrituras epicóricas paleohispánicas desaparece progresivamente a medida que avanza la romanización de sus territorios respectivos, siendo residuales los testimonios que pueden datarse ya a finales del s. I a. C., aunque quizás alguno llegue incluso a principios del s. I d.C., no obstante, normalmente se trata de esgrafiados dudosos. La inscripción ibérica más moderna que no presenta dudas ni en cuanto a la datación de soporte, ni en la identificación de la escritura como nororiental en un fragmento de terra sigillata Itálica de Baetulo/baitolo (Badalona), de la forma Goudineau 1, del último cuarto del s. I a. C. (Simón 2013, 171). 


\section{Escrituras}

\subsection{Las escrituras nororientales}

\subsubsection{La escritura ibérica nororiental}

La escritura ibérica nororiental, también conocida como ibérica levantina, se atestigua en el cuadrante noreste de la península ibérica desde la segunda mitad del siglo $\mathrm{V}$ a. C. hasta el primer cuarto del siglo I d.C. en c. 2.250 inscripciones en lengua ibérica. La dirección de escritura va en la mayoría de los casos de izquierda a derecha, pero ocasionalmente también de derecha a izquierda. Normalmente los textos presentan separadores de palabras formados por grupos de puntos en vertical, siendo el de dos puntos el más común.

La escritura ibérica nororiental presenta tres variantes principales, en función del número de signos que aparecen formando dualidades: la escritura no-dual, la dual estándar y la dual ampliada.

\subsubsection{La escritura ibérica nororiental no-dual}

La escritura no dual es la utilizada en cerca del $60 \%$ del total de inscripciones ibéricas nororientales y presenta el conjunto más básico de signos (fig. 5).

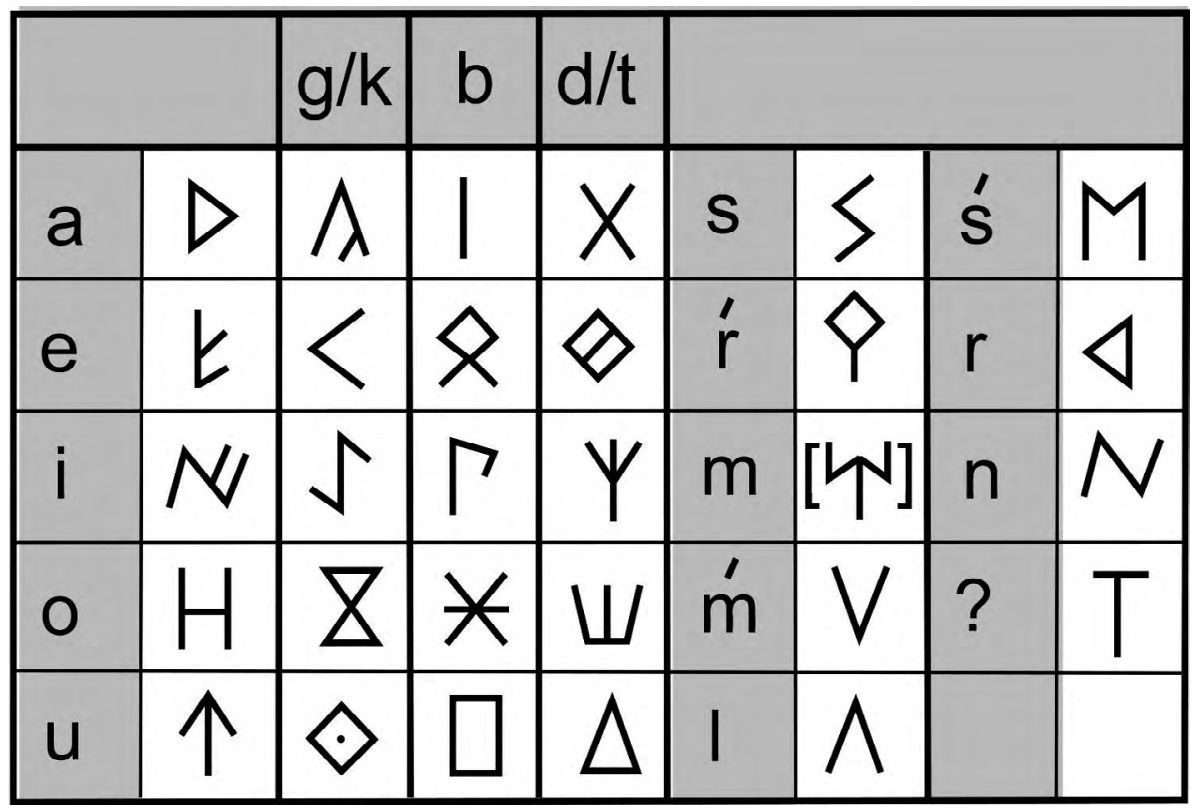

Fig. 5. Signario de la escritura ibérica nororiental no-dual. 
A pesar de que la lengua ibérica sí que distingue las consonantes sordas de las sonoras, esta escritura no permite hacer esta distinción. Los últimos estudios confirman que la escritura ibérica no dual es característica de las inscripciones más recientes (siglos II y I a. C.) y que su origen podría ser la simplificación de una escritura ibérica dual más antigua. El abecedario se reduce a 28/29 signos, en su mayoría tomando la variante sin marcar de cada par dual. Se certifica directamente en los abecedarios de L'Esquirol, Can Rodon, La Tor de Querol y Val de Alegre (fig. 6) (Ferrer 2014a, 2014b).

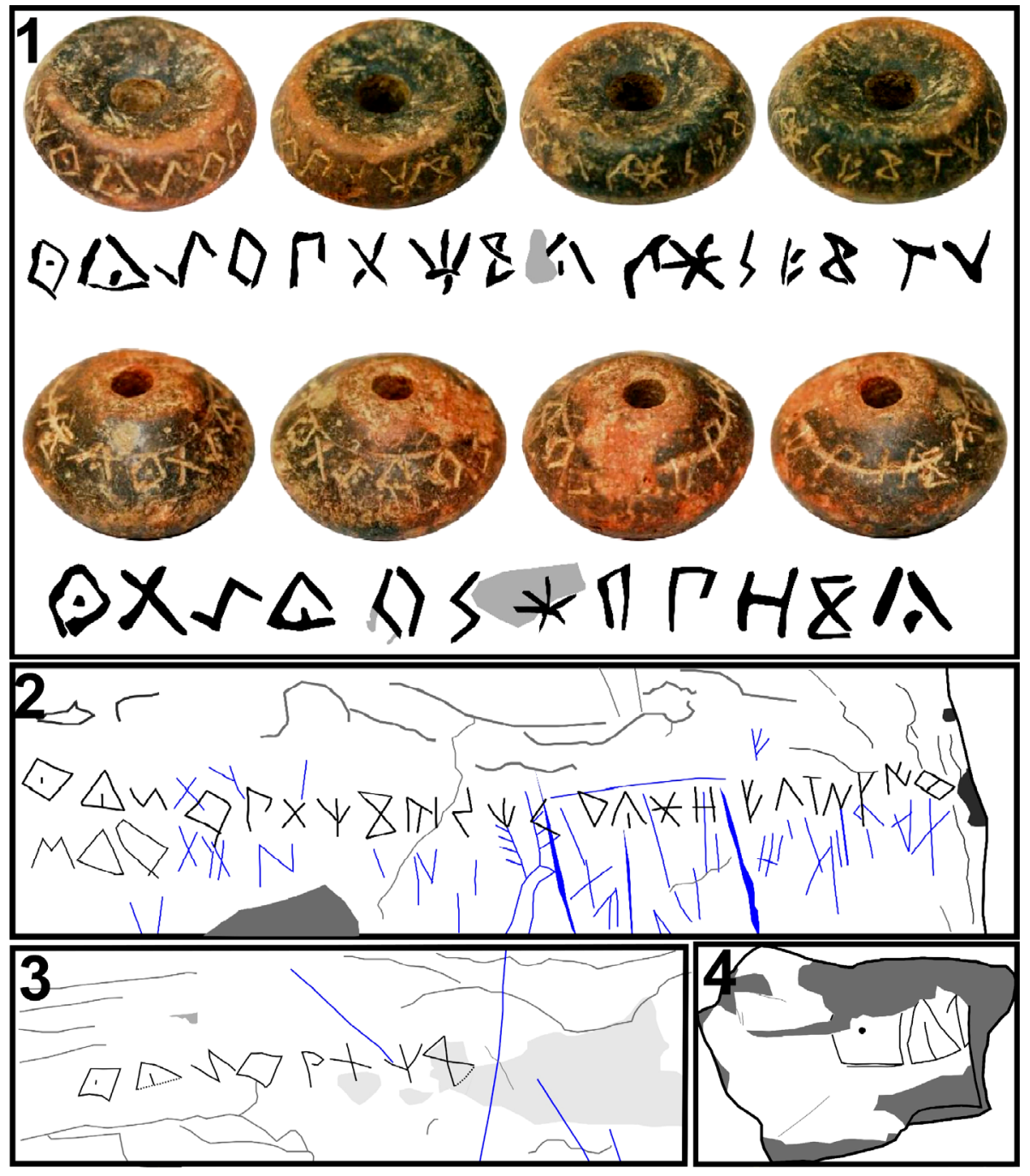

Fig. 6. Abecedarios nororientales no duales: Can Rodon (1), L'Esquirol (2), La Tor de Querol (3) y Val de Alegre (4). 
El repertorio básico de signos consiste en cinco signos vocálicos, a $(P)$, e $(\mathfrak{k}), \mathbf{i}\left({ }^{\mathbb{N}}\right), \mathbf{o}(H)$ y $\mathbf{u}(\uparrow)$; cinco signos silábicos para las oclusivas dentales, ta $(X)$, te $(\diamond)$, ti $(Y)$, to $(\bigvee)$ y tu $(\triangle)$, cinco para las oclusivas velares, ka $(\wedge)$ $\mathbf{k e}(<), \mathbf{k i}(\checkmark), \mathbf{k o}(\mathrm{Z})$ y ku $(\diamond)$, y cinco para las oclusivas labiales, ba $(\mathrm{I}), \mathbf{b e}(\widehat{\mathrm{X}})$, bi $\left(\ulcorner)\right.$, bo $(*)$ y bu $(\square)$; cuatro nasales, $\mathbf{n}\left(\Upsilon^{\top}\right), \mathbf{m}\left({ }^{\top}\right), \mathbf{m}(\bigvee)$ y probablemente

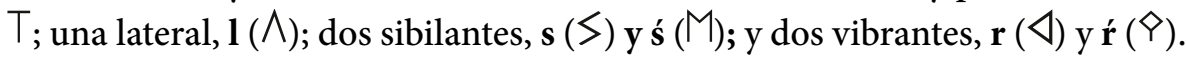
No es seguro si el signo nasal $\mathbf{m}\left({ }^{\top}\right)$ debe considerarse como parte del abecedario no dual, ya que su aparición es muy rara en las inscripciones no duales y es uno de los dos signos que faltan en el abecedario no dual del Esquirol.

La naturaleza fonética exacta de las dos sibilantes, las dos vibrantes y la serie de nasales aún no se ha dilucidado y su transcripción mediante diacríticos es una convención para reflejar gráficamente su oposición. Esto es especialmente obvio con respecto a la transcripción del signo nasal ḿ $(\bigvee)$ con un diacrítico, ya que se acepta que pudiera tener un componente nasal y un componente vocálico y, por lo tanto, la transcripción no pretende reflejar su valor fonético.

El signo nasal, $\mathrm{T}$ sin una transcripción consensuada, que aparece como I en las primeras inscripciones, se consideró inicialmente como un alógrafo de $\mathbf{m}\left({ }^{\Upsilon}\right)$ o $\mathbf{m}(\bigvee)$; pero recientemente se ha confirmado que es un signo autónomo, ya que aparece en el abecedario de Ger, y probablemente también en el abecedario de La Tor de Querol, junto con $\mathbf{m}\left({ }^{\Upsilon}\right)$ y $\mathbf{m}(\bigvee)$. En el abecedario de Ger aparece junto con ḿ $(\bigvee)$ en un contexto donde los signos con valores relacionados aparecen uno al lado del otro, circunstancia que confirmaría su naturaleza nasal.

\subsubsection{La escritura ibérica nororiental dual estándar}

La escritura dual consiste en el uso de signos con dos variantes, cada una de ellas con un valor distinto, que se diferencian entre sí al presentar un trazo adicional (fig. 7).

El signo con el trazo adicional se identifica como la variante compleja, y el que no tiene el trazo, como simple. Este comportamiento fue identificado por primera vez por Joan Maluquer de Motes (1968) y fue desarrollado más tarde por otros investigadores (De Hoz 1985; Correa 1992) que completaron el subconjunto de signos que pertenecen al sistema y también explicaron satisfactoriamente el significado de la marca, que permitía diferenciar la sonora (signo simple) de la sorda (signo complejo). Sin embargo, aunque inicialmente se pensó que el sistema se aplicaba a todas las oclusivas, se demostró 
(Ferrer 2005) que una de las supuestas variantes simples para el signo bo (* / $X)$, debía ser reinterpretada como la variante compleja para ta $(X / X)$. Esta reorganización le dio una mayor consistencia al sistema al excluir los signos labiales, cuya presencia era irregular, puesto que todos los indicios apuntaban a que no existía en ibérico la oposición entre labiales sordas y sonoras.

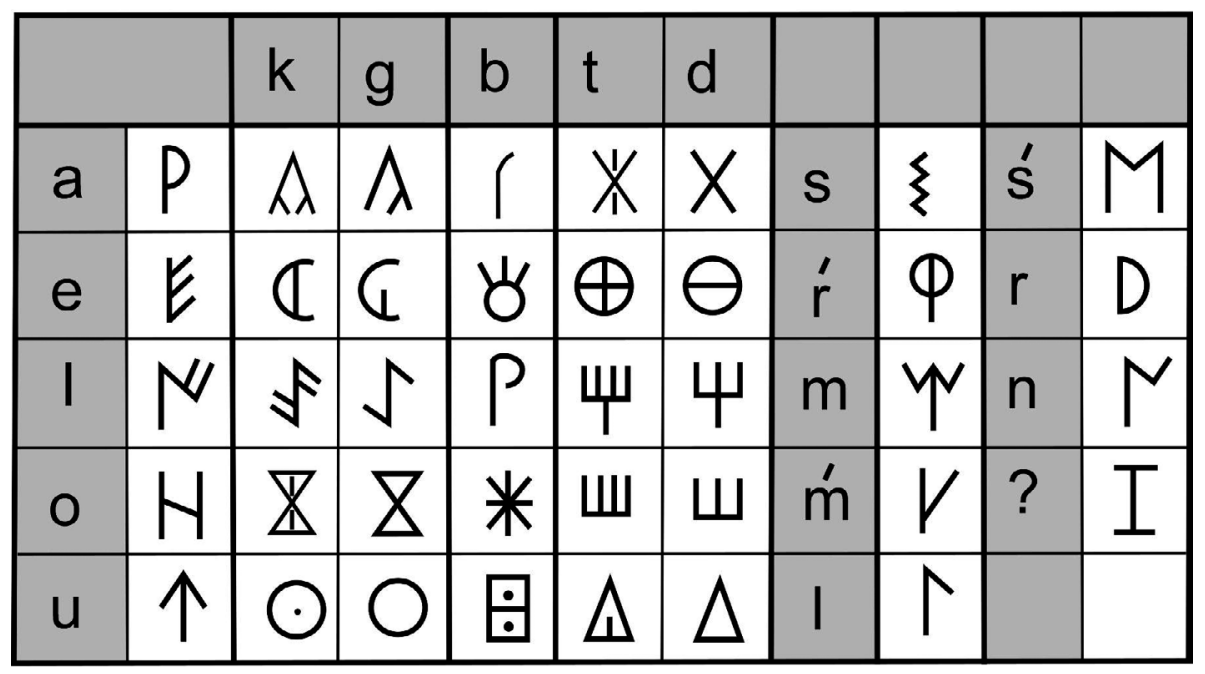

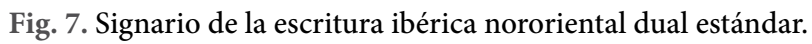

Esta escritura se usa en las inscripciones más antiguas (del siglo V al III a. C.) y representa aproximadamente el 35\% del corpus ibérico nororiental. Sin embargo, en inscripciones cortas, no se puede establecer fácilmente si el sistema que se está utilizando es la escritura dual o el no dual. Esta escritura llega a 39 signos, ya que solo duplica signos silábicos dentales o velares: ta/da $(X / X)$, te/de $(\bigoplus / \Theta)$, ti/di $(\Psi / \Psi)$, to/do $(Ш / Ш)$, tu/du $(\Delta / \Delta)$, ka/ga $(A / \wedge)$, ke/ ge $(\mathbb{C} / C)$, ki/gi $(\uparrow / \uparrow)$, ko/go $(\mathbb{Z} / Z)$ y ku/gu $(\odot / \bigcirc)$. La exclusión de la serie

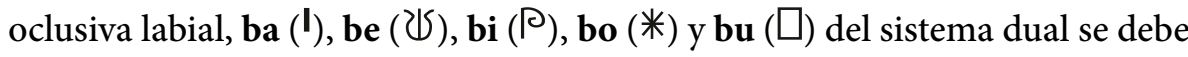
a la baja productividad de la sorda /p/ en la lengua ibérica, como se puede observar particularmente en las inscripciones greco-ibéricas más largas, como la lámina de plomo de La Serreta de Alcoi (BDH A.04.01). La escritura dual estándar está atestiguada en los abecedarios de Ger, Bolvir y La Tor de Querol (fig. 8) (Ferrer 2013a; 2013b; 2014a; 2014b). 


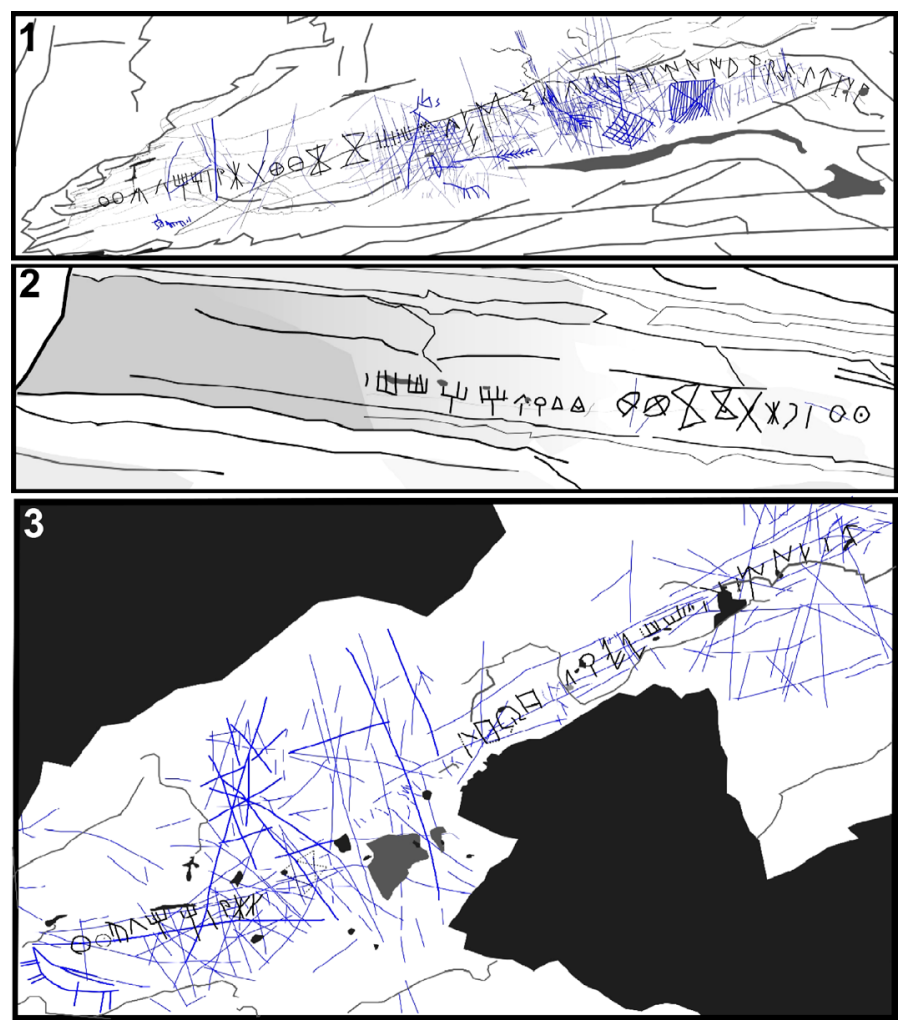

Fig. 8. Abecedarios nororientales duales estándar: Ger (1), Bolvir (2) y La Tor de Querol (3).

Además, hay varios signos extremadamente raros para los que no se puede decir si son signos independientes o variantes locales de algún signo ya conocido. Uno de ellos, el signo, con la forma de una B ( $b)$, ha sido confirmado recientemente como un alógrafo de la vibrante $\mathbf{r}(D)$, ya que aparece en dos nuevas inscripciones de Vilademuls (Girona) insertadas en dos términos bien conocidos, baikar y egiar (Ferrer y Sánchez 2017). Existe otro signo raro, similar a una espiga con dos $(\nVdash)$ o tres trazos $(\mathbb{\Downarrow})$, que a veces se transcribe como e $(E / E)$, como en la leyenda monetal sesars (A.44); sin embargo, también podría ser una variante invertida de la forma compleja del signo u ( $(\uparrow)$, una variante hipotética del signo para bo (*), o incluso un signo con otro valor diferente.

\subsubsection{La escritura ibérica nororiental dual ampliada}

Otro tipo de escritura dual, que alcanzaría 46 signos (fig. 9), amplía el repertorio de dualidades a las vocales, a/á (D/P), e/é $(\mathbb{E} / E), \mathbf{i} / \mathbf{i}(\mathbb{N} / \mathbb{N}), \mathbf{o} / \mathbf{o}(H / / H)$ y $\mathbf{u} / \mathbf{u}(\uparrow / \uparrow)$, y a algunas consonantes continuas, $\mathbf{s} / \hat{\mathbf{s}}(\zeta / \xi)$ y $\dot{\mathbf{r}} / \check{\mathbf{r}}(\Phi / \Upsilon)$. 


\begin{tabular}{|c|c|c|c|c|c|c|c|c|c|c|}
\hline & & & $k$ & $g$ & $b$ & $\mathrm{t}$ & $d$ & $?$ & $?$ & \\
\hline á $P$ & a & $D$ & $A$ & $\lambda$ & 1 & X & $X s$ & $\zeta$ & $\hat{s} \xi \xi$ & $s^{\prime} M$ \\
\hline él & 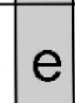 & $E$ & $\mathbb{1}$ & 1 & $\mho$ & $\oplus$ & $\theta \mid \dot{r}$ & $\phi$ & $\check{r}$ & $r 0$ \\
\hline$i N$ & & $N$ & F & 1 & $P$ & $\Psi$ & ५ & $\uparrow$ & & $n \mid \mathrm{N}$ \\
\hline ó & & $\mathrm{N}$ & $\mathbb{Z}$ & 8 & 米 & Ш & $\sqcup \mathrm{m}^{\prime}$ & $Y$ & & \\
\hline ú & & $\uparrow$ & (2) & $\odot$ & $\square$ & $\Delta$ & $\Delta \mid \mathrm{I}$ & $\uparrow$ & & $?$ ? \\
\hline
\end{tabular}

Fig. 9. Signario de la escritura ibérica nororiental dual ampliada.

Esta variante se atestigua en los abecedarios de Castellet de Bernabé (fig. 10.1) y del Tos Pelat (fig. 10.3) (Ferrer 2009; Burriel et al. 2011). Las inscripciones que muestran dualidades también para consonantes y vocales continuas son escasas: representan solo el 5\% del total y se concentran en los alrededores de Llíria (València).

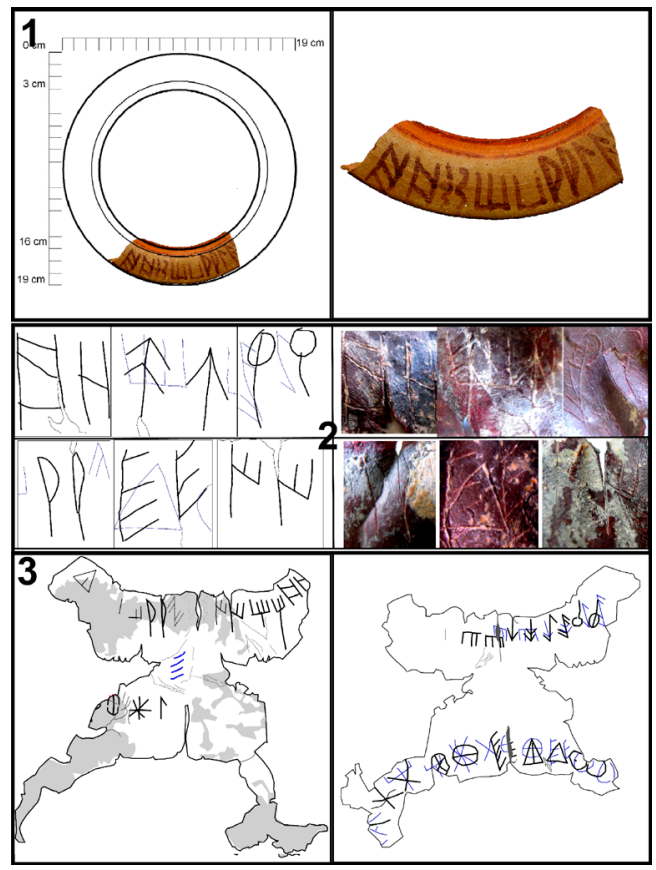

Fig. 10. Abecedarios nororientales duales ampliados: Castellet de Bernabé (1) y Tos Pelat (2 y 3$)$. 
Todas las dualidades para las vocales que aparecen en el abecedario de Tos Pelat (fig. 8.2), y o/ó (H/A) y a/á ( $(0 / P)$ lo hacen también en el abecedario de Castellet de Bernabé (fig. 8.1). La dualidad vocálica mejor representada en las inscripciones es la dualidad del signo e $(E / E)$, ya que aparece explícitamente en algunas inscripciones pintadas de Llíria. Sin embargo, hasta ahora no ha sido posible encontrar una explicación fonética plausible para justificar esta oposición gráfica entre las vocales marcadas y no marcadas (Ferrer 2015).

Entre las consonantes, la dualidad mejor representada es la de la vibrante ŕ $(\$ / \Phi)$ que se muestra explícitamente en el abecedario de Tos Pelat, en varias inscripciones largas en plomo y en algunos tituli picti de Llíria. Sobre la base del uso de esta misma dualidad exacta en la escritura ibérica suroriental (Ferrer 2010), pero con el significado de la marca invertido, donde ř aparece principalmente en un contexto intervocálico, he propuesto que la variante marcada en la escritura ibérica nororiental, $\dot{\mathbf{r}}(\Phi)$, fuese la vibrante simple, mientras que la variante sin marcar, $\check{\mathbf{r}}($ ( ), debería ser la múltiple. Respecto a las sibilantes $\mathbf{s}(そ / \xi)$, atestiguadas en el abecedario del Castellet de Bernabé y esporádicamente en otras inscripciones, he propuesto que la sibilante marca$\mathrm{da}, \hat{\mathbf{s}}(\xi)$, fuese la sorda (fortis), mientras que la variante sin marcar, $\mathbf{s}(\zeta)$, fuese la sonora (lenis), como sucede con las consonantes oclusivas.

En la escritura dual ampliada hay un signo poco frecuente, que comúnmente se ha considerado como una variante de e $(k)$, e7, o ka $(\wedge)$, ka7. Sin embargo, considerando su forma, también podría interpretarse como una variante marcada de $\mathbf{l}(\uparrow)$; además, en el abecedario de Castellet de Bernabé se encuentra siguiendo a la lateral $\mathbf{l}$, aunque si fuese un par dual, el orden estaría invertido en relación con el orden complejo-simple habitual. De hecho, en otras inscripciones aparece principalmente en este mismo orden, siempre precedido por 1 ( $\uparrow)$; por lo tanto, la hipótesis de que es una variante compleja de $\mathbf{l}$ debe rechazarse, aunque lo podría haber sido originalmente, en alguna escritura paleohispánica antecesora. En algunos textos parece plausible suponer que tenía un componente vocálico (Rodríguez Ramos 2001). Se representa arbitrariamente en este documento como â, en lugar de á, como se transcribe en otras obras, para evitar la confusión con la variante compleja de a.

\subsubsection{La escritura celtibérica}

La escritura celtibérica es claramente una adaptación de la escritura ibérica nororiental a las especificidades de la lengua celtibérica. Esta escritura está documentada entre finales del siglo III a. C. y principios del siglo I d. C. 
en algo más de 250 inscripciones de más de un signo, incluyendo leyendas monetales, que se localizan en interior de la península ibérica, principalmente en las provincias de Zaragoza, Teruel, Guadalajara y Soria (Jordán 2019).

La adaptación de la escritura ibérica a la lengua celtibérica es casi directa. Su conjunto básico de signos consiste en cinco signos vocálicos, a $(P), \mathbf{e}(\mathfrak{V})$, $\mathbf{i}\left({ }^{N}\right)$, o $(H)$ y u $(\uparrow)$; cinco signos silábicos para las oclusivas dentales, ta $(X)$, te $(\diamond)$, ti $(\Psi)$, to $(\amalg)$ y tu $(\triangle)$, cinco signos silábicos para las oclusivas velares, ka $($ ^), ke $(<), \mathbf{k i}(\checkmark), \mathbf{k o}(\nabla)$ y ku $(\diamond)$, y cinco signos silábicos para las oclusivas labiales, ba $(\mathrm{l})$, be $(\widehat{X})$, bi $(\Gamma)$, bo $(*)$ y bu $(\square)$; y signos consonánticos para dos signos nasales, una lateral, $\mathbf{l}(\uparrow)$, dos sibilantes, $\mathbf{s}(\zeta)$ y ś $(M)$, y una vibrante $\mathbf{r}(\widehat{Y})$ (fig. 11). No es clara la oposición exacta entre las dos sibilantes $\mathrm{y}$ otras particularidades fonéticas de la escritura celtibérica.

\begin{tabular}{|c|c|c|c|c|c|c|c|c|c|c|}
\hline & & $\mathrm{g}$ & $\mathrm{k}$ & $\mathrm{b} / \mathrm{p}$ & d & $\mathrm{t}$ & & & & \\
\hline$a$ & $P$ & $\lambda$ & $A$ & 1 & $X$ & * & $z$ & $\xi$ & $\mathrm{m}$ & $\psi$ \\
\hline e & $\$$ & $C$ & $G$ & 3 & $\theta$ & $\theta$ & $\mathrm{s}$ & $M$ & $\mathrm{n}$ & $\mathrm{N}$ \\
\hline $\mathrm{i}$ & $N$ & 5 & $\$$ & $P$ & ب & $\psi$ & $r$ & $\phi$ & 1 & $\uparrow$ \\
\hline 0 & $\mathrm{H}$ & Z & $\mathbb{Z}$ & 米 & $\sqcup$ & ш & & & & \\
\hline $\mathrm{u}$ & $\uparrow$ & 0 & $\odot$ & $\square$ & $\Delta$ & $\triangle$ & & & & \\
\hline & & $g$ & $k$ & $b / p$ & $d$ & $\mathrm{t}$ & & & & \\
\hline a & $P$ & $\lambda$ & A & 1 & $X$ & * & z & $\xi$ & $\mathrm{m}$ & $N$ \\
\hline $\mathrm{e}$ & $\$$ & $C$ & $G$ & $w$ & $\otimes$ & $\theta$ & $\mathrm{s}$ & $M$ & $n$ & V \\
\hline i & $N$ & 5 & $s$ & $P$ & ५ & 4 & $r$ & $\phi$ & 1 & $T$ \\
\hline o & $\mathrm{H}$ & $\nabla$ & $\mathbb{Z}$ & 米 & $\sqcup$ & ш & & & & \\
\hline $\mathrm{u}$ & $\uparrow$ & 0 & $\odot$ & $\square$ & ^ & $\Delta$ & & & & \\
\hline
\end{tabular}

\begin{tabular}{|c|c|c|c|c|c|c|c|c|}
\hline & & $\mathrm{g} / \mathrm{k}$ & $\mathrm{b} / \mathrm{p}$ & $\mathrm{d} / \mathrm{t}$ & & & & \\
\hline$a$ & $\nabla$ & $\lambda$ & 1 & $X$ & $z$ & $s$ & $\mathrm{~m}$ & $\Psi$ \\
\hline $\mathrm{e}$ & $t$ & $\leqslant$ & 8 & $\diamond$ & $\mathrm{s}$ & $M$ & $\mathrm{n}$ & $N$ \\
\hline $\mathrm{i}$ & $N$ & 5 & $\Gamma$ & $\psi$ & $r$ & $\diamond$ & $I$ & $T$ \\
\hline 0 & $\mathrm{H}$ & 8 & $*$ & $\Psi$ & & & & \\
\hline $\mathrm{u}$ & 个 & $\diamond$ & $\square$ & $\Delta$ & & & & \\
\hline & & $g / k$ & $\mathrm{~b} / \mathrm{p}$ & $\mathrm{d} / \mathrm{t}$ & & & & \\
\hline$a$ & $p$ & $\lambda$ & 1 & $X$ & $\mathrm{z}$ & 5 & $\mathrm{~m}$ & $N$ \\
\hline $\mathrm{e}$ & E & $C$ & $w$ & $\otimes$ & $\mathrm{s}$ & $M$ & $\mathrm{n}$ & $r$ \\
\hline$i$ & $N$ & 5 & $\Gamma$ & 4 & $r$ & $\varphi$ & 1 & $\Gamma$ \\
\hline 0 & $\mathrm{H}$ & 8 & * & ш & & & & \\
\hline $\mathrm{u}$ & $\uparrow$ & $\diamond$ & $\square$ & $\Delta$ & & & & \\
\hline
\end{tabular}

Fig. 11. Signarios de las escrituras celtibéricas: Oriental dual, oriental no dual (arriba), occidental dual y occidental no dual (abajo).

Las únicas innovaciones son la eliminación de una de las dos vibrantes ibéricas $(\checkmark)$ y la simplificación de las nasales. Dependiendo de cómo se adaptaron las nasales ibéricas, la escritura celtibérica se clasifica como occidental u oriental. En la escritura occidental, el signo ibérico $\mathbf{n}\left(\Gamma^{\top}\right)$ representa $/ \mathrm{m} /$ y el signo ibérico ḿ $(Y)$ representa $/ \mathrm{n} /$, mientras que en la escritura oriental el signo ibérico $\mathbf{n}(\Upsilon)$ representa $/ \mathbf{n} /$ y el signo ibérico $\mathbf{m}\left({ }^{\top}\right)$ representa $/ \mathrm{m} /$. 
La variante occidental representa el $42 \%$ del total, mientras que la oriental representa el $58 \%$ del total. La distribución geográfica de las variantes de acuerdo con el principio descrito anteriormente es coherente; pero hay algunas excepciones debido a particularidades locales y a objetos que por su naturaleza es plausible que se hayan localizado fuera de su lugar de origen. En algunas inscripciones se usa el cuarto signo ibérico nasal $(T)$; pero en este momento no está claro qué valor representa en la escritura celtibérica e incluso si esas inscripciones son realmente celtibéricas.

De forma similar a la escritura ibérica nororiental, también se identifica un sistema dual en la escritura celtibérica (Ferrer 2005; Jordán 2005; 2007; 2019). Aparentemente con el mismo propósito de diferenciar los signos silábicos dentales y velares sordos de los sonoros: ta/da $(X / X)$, te/de $(\bigoplus / \ominus)$, ti/

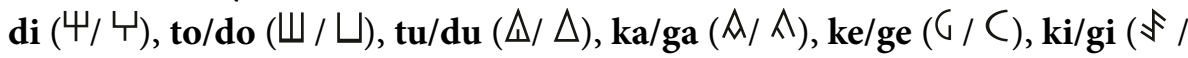
$\checkmark), \mathbf{k o} / \mathbf{g o}(\mathbb{Z} / \mathrm{Z})$ y ku/gu $(\odot / \bigcirc)$.

La escritura celtibérica también presenta una escritura redundante donde los signos silábicos siempre van seguidos de la vocal asociada a este mismo signo silábico. El uso de la redundancia se documenta en solo nueve inscripciones (siete entre las de tipo occidental y dos entre las de tipo oriental). Ocho de ellas son duales, y solo una de ellas es no-dual del tipo occidental. Por lo tanto, no hay inscripciones redundantes entre las inscripciones orientales no duales, lo cual es un hecho relevante, ya que representan el grupo principal dentro del corpus celtibérico. Esta distribución indica que la escritura redundante es característica de las inscripciones más antiguas, las duales, en lugar de una innovación. Probablemente, tal como ocurre en la escritura del sudoeste, la redundancia en la escritura celtibérica parece ser un uso anómalo del sistema silábico vinculado al proceso de aprendizaje de la escritura por parte de algunas escuelas concretas de escribas.

En cuanto a la génesis de la escritura celtibérica, el primer modelo (fig. 12.A) fue el propuesto por J. de Hoz (1986b), en el cual la escritura occidental era la más antigua, y la primera en ser adaptada de la escritura ibérica nororiental, ya que en general presenta una paleografía más arcaica. En este modelo se consideró que la escritura oriental era el resultado de una reforma ortográfica interna. Un segundo modelo (fig. 12.B) es el propuesto por Rodríguez Ramos (1997), y también considerado como plausible por De Hoz (1986b). En este modelo, la escritura celtibérica tendría un doble origen ibérico, siendo el modelo occidental una adaptación temprana de una escri- 
tura ibérica nororiental arcaica, mientras que la escritura oriental sería una adaptación de una más reciente.

La identificación de la escritura celtibérica dual apuntaba a la posibilidad de que el origen de la escritura occidental fuera la escritura dual nororiental, mientras que la escritura oriental sería una adaptación de la escritura no dual ibérica (fig. 12.C). La única adición al modelo anterior sería la identificación de la escritura occidental no dual como una simplificación de la escritura occidental dual. Además, el uso en la escritura occidental dual de las variantes de ti y to con dos y tres trazos, ti/di ( favorable para sostener que la adopción de esta escritura por los celtiberos se produjo por los contactos con los íberos de Llíria (València), ya que las variantes con dos trazos de ti y to son casi exclusivas de esta zona.

Hoy en día, teniendo en cuenta la reciente publicación de la falera de Armuña (Velaza e. p.), que es del tipo oriental y presenta una dualidad explícita para ka $(A / \AA)$, está claro que también había una escritura dual oriental (fig. 12.D). El doble origen ibérico sigue siendo la mejor alternativa; pero debe retroceder a cronologías duales para las escrituras occidentales y orientales. Sin embargo, la distribución de las inscripciones duales y no duales en la escritura oriental y occidental se invierte: mientras que la mayoría de las inscripciones orientales no son duales (70\%), la mayoría de las inscripciones occidentales sí lo son (75\%). Esto implica que la escritura occidental se desarrolló esencialmente en una cronología dual, mientras que la escritura oriental se desarrolló básicamente en un momento en el que el dual ya no estaba en uso. Esto podría deberse a la adopción más temprana de la escritura occidental o la romanización más temprana de la Celtiberia oriental, o, mejor aún, a una combinación de ambos factores (Ferrer 2017a; e. p.b).

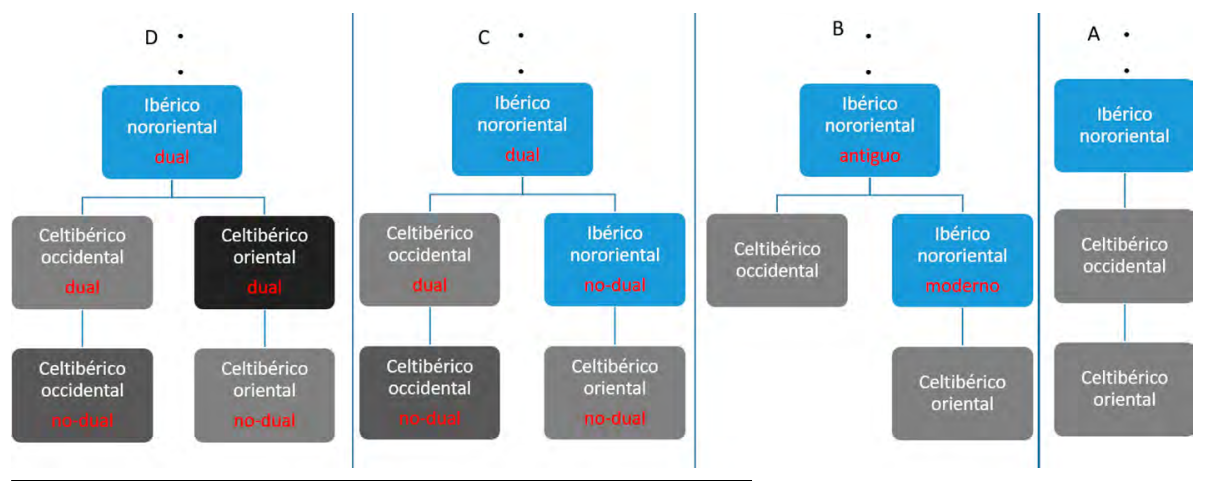

Fig. 12. Modelos genealógicos de las escrituras celtibéricas:

De Hoz (A), Rodríguez Ramos (B), Ferrer i Jané (C y D). 
Con respecto a la cronología de la escritura celtibérica más antigua, inicialmente se creyó que fue adoptada durante el siglo II a. C., en el contexto de los contactos culturales ocurridos durante la romanización a lo largo del Valle del Ebro. Hoy en día, la identificación de un sistema dual en las dos escrituras celtibéricas es un argumento sólido para defender una transmisión más antigua, ya durante el siglo III a. C., y con dos formas diferentes de penetración: a través del área edetana para la escritura occidental y a través del Valle del Ebro para la escritura oriental.

\subsection{Las escrituras meridionales}

\subsubsection{La escritura ibérica meridional}

La escritura ibérica suroriental está atestiguada en el cuadrante suroriental de la península ibérica desde el siglo IV a. C. hasta el I a. C. en unas setenta inscripciones en lengua ibérica; sin embargo, las inscripciones más occidentales probablemente representan una o varias lenguas diferentes, $y$ posiblemente también nuevas escrituras meridionales.

En cuanto al sentido de la escritura suroriental, los textos suelen escribirse de derecha a izquierda, pero también, en algunos casos, de izquierda a derecha. El separador de palabras más común consiste en una barra vertical, pero también es común el uso de dos, tres o incluso más puntos verticales.

Los principales recursos para su desciframiento son las similitudes con el alfabeto fenicio y la escritura ibérica nororiental para los signos compartidos. Además, también son útiles los datos internos derivados de las particularidades de la escritura del sudoeste, donde los signos silábicos siempre van seguidos de una vocal en una aparente redundancia. Finalmente, dado que las dos escrituras ibéricas representan la misma lengua, también es posible identificar algunos elementos léxicos atestiguados en la escritura nororiental, también en la escritura suroriental.

A diferencia de la escritura ibérica nororiental, la escritura ibérica suroriental no puede considerarse totalmente descifrada, ya que el valor de muchos signos aún es incierto (fig. 13). El valor para los signos a (A), i (\), $\mathbf{l}(1), \mathbf{n}\left({ }^{(}\right), \dot{r}\left({ }^{(}\right)$, $\mathbf{s}($ 丰), ś $(M)$, ta $(+)$, tu $(\triangle)$, ka $(\wedge)$, ke $(\supset)$ y ko $(\bowtie)$ ha sido aceptado unánimemente desde la publicación de los primeros estudios (Gómez-Moreno 1943; 1961; Schmoll 1961; Maluquer 1968; De Hoz 1976), ya que en algunos casos coincide con los valores de las mismas formas en la escritura ibérica nororiental y en el alfabeto fenicio. En estudios recientes también hay una unanimidad 
casi total con respecto a la identificación de los signos o $(\mp), \mathbf{t i},(\ominus) \mathbf{u}(4$ e $(\bigcirc)$ y bi $(\uparrow)$ gracias a los paralelos léxicos obtenidos de la comparación con los textos ibéricos nororientales. Hay un grupo de signos para los cuales todavía no hay un consenso absoluto (fig. 14), pero una interpretación concreta

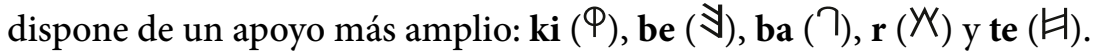

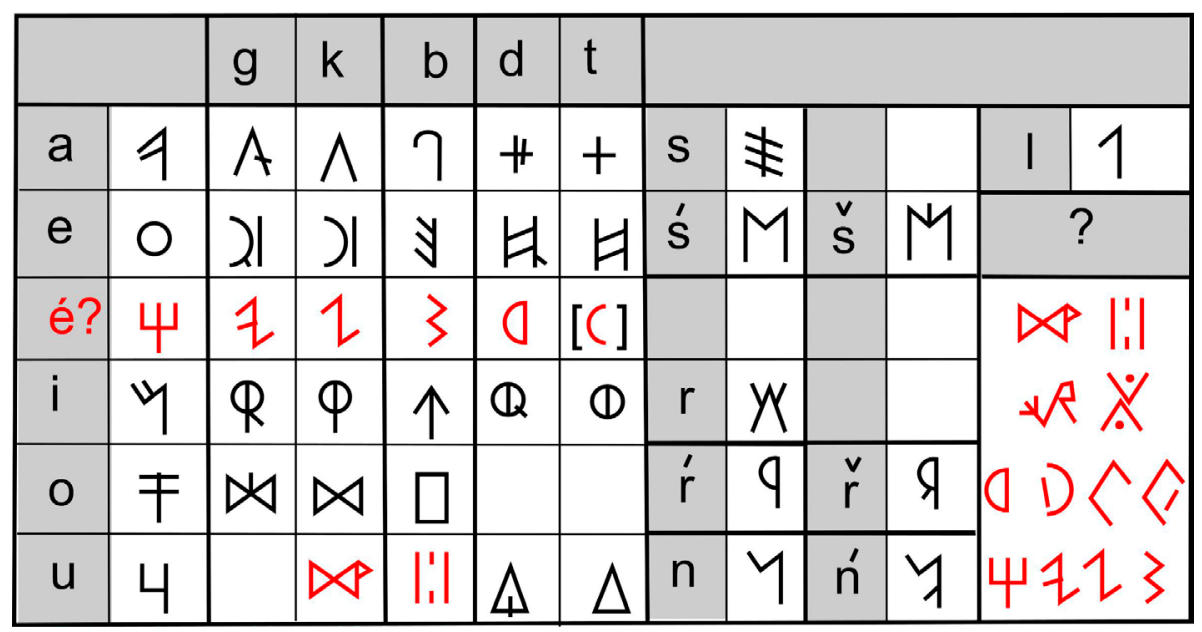

Fig. 13. Signario de la escritura ibérica suroriental (dual).

Aunque el signo G27 (秋) se encontraría en el grupo anterior (fig. 14), ya que existe un cierto consenso en considerar que tiene el valor bo, a mi parecer, desde el punto de vista paleográfico parece más razonable considerarlo como una variante compleja del signo ko $(\bowtie)$ en el sistema dual, como se explicará más adelante.

El signo S47a $(\square)$ no tiene un valor de consenso, pero se interpreta mayoritariamente con bu, ya que este es su valor en la escritura ibérica nororiental; sin embargo, a mi parecer, la evidente relación de parentesco entre las diversas escrituras meridionales indica que plausiblemente sea bo, el mismo que en la escritura sudoeste.

Hay otro grupo de signos sin un valor aceptado universalmente que se clasifican principalmente como signos pendientes de identificación, S48 (Ч), S45 ( 2$)$, S81 ( $(9)$ y S42 (3); sin embargo, como se explica en el apartado final, podrían encajar en una serie silábica adicional, compuesta por una vocal extra, más sus signos silábicos correspondientes para velar, dental y labial. 


\begin{tabular}{|c|c|c|c|c|c|c|c|}
\hline Sign & Ref. & $\mathbf{J U}$ & JdH & JAC & JRR & AMF & JFJ \\
\hline 3 & S42 & $?$ & ba & $?$ & ke & be & bé? \\
\hline 0 & S81 & $?$ & $?$ & $?$ & to & ke / ́r / to & té? \\
\hline$\Psi$ & S48 & e & ti & $?$ & $\mathbf{e}$ & e & é? \\
\hline 官 & S47a & te & ¿? & $?$ & bo/bu & bu & bo \\
\hline 1 & S45 & ki & ki & $?$ & ku & gi & ké? \\
\hline$y$ & S41 & be & i? & be & be & be & be \\
\hline 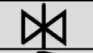 & G27 & bo & bo & bo & bo & bo & go \\
\hline 1 & S60 & ba & bi & ba? & ba & ba & ba \\
\hline$\Phi$ & S46 & $?$ & ki & $?$ & ki & $\mathbf{k i}$ & ki \\
\hline 9 & S46 & e & ki & $?$ & e & ki & gi \\
\hline$E$ & S47f & te? & te & te & te & te & te \\
\hline $\bar{r}$ & S56 & $\dot{\mathbf{r}}$ & $?$ & $\mathbf{r}$ & $\mathbf{r}$ & $\mathbf{r}$ & $\mathbf{r}$ \\
\hline
\end{tabular}

Fig. 14. Valores más controvertidos de la escritura ibérica suroriental: $M L H$ III [JU]; De Hoz 2011 [JdH]; Correa 1985; 1993-1994; 2004 [JAC]; Rodríguez Ramos 2002a; 2006 [JRR]; Faria 1990-1991 [AMF]; Ferrer 2010 [JFJ].

En trabajos anteriores he propuesto la posibilidad de que la escritura ibérica suroriental también tuviera una modalidad de escritura dual (Ferrer 2010), como sucede en la escritura ibérica nororiental; pero con el significado de la marca invertida: la variante compleja representaría la sorda, mientras que la variante simple representaría la sonora. En esta hipótesis se considera la existencia de dualidades para las oclusivas dentales y velares: ta/da $(+/ \mathcal{X}$

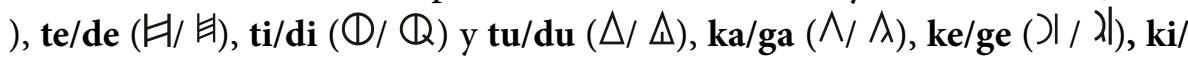
gi $(\mathrm{P} / \varphi)$ y ko/go $(\bowtie / \bowtie)$. Sin embargo, las dualidades de to/do y ku/gu aún no se pueden identificar; en cambio, es posible identificar dualidades para los signos S45.2/S45.4 ( $/ Z$ ), pero no con claridad para el signo S81 ( $)$. Estas dualidades podrían coincidir respectivamente con los signos silábicos ku/ gu y to/do o los signos silábicos velares y dentales de una hipotética serie de seis vocales. El sistema dual ibérico suroriental también tiene dualidades para

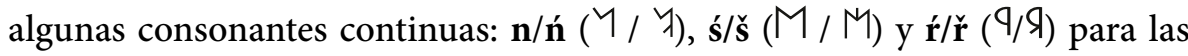
que, si el mecanismo funciona igual que en las oclusivas, se supone debería diferenciar en general los sonidos fortis ń $(~(\nearrow)$ frente a lenis $\mathbf{n}(\)$, que en el caso de la sibilante podría ser sonora š $(M)$ frente a sorda ś $(M)$ y en el caso de la vibrante múltiple $\check{\mathbf{r}}(Я)$ frente a simple $\dot{\mathbf{r}}\left({ }^{(}\right)$. De hecho, todas las inscripciones ibéricas surorientales largas parecen ser duales, lo que implica que hasta ahora no hay evidencia de la existencia de una escritura ibérica suroriental no 
dual. Sin embargo, es plausible que pudiera haber existido, como sucede con las escrituras nororientales, tanto ibérica como celtibérica.

\subsubsection{La escritura del sudoeste}

La escritura del sudoeste se emplea en cerca de un centenar de inscripciones que representan un idioma de filiación desconocida. Casi todas son grandes estelas de piedra que se encuentran en el cuadrante sudoccidental de la península ibérica, quizás en un período que va desde el siglo VII hasta el siglo IV a. C. Algunos estudiosos utilizan la denominación de tartésica de manera restrictiva para identificar solo la escritura en la que se escriben las inscripciones de la zona nuclear tartésica, dejando la denominación del sudoeste para las inscripciones de la zona periférica occidental, que comprenden la mayor parte del grupo. ${ }^{3}$

En 1961, U. Schmoll descubrió la característica más significativa de esta escritura, la llamada "redundancia vocálica". Implica que cada signo silábico es seguido casi siempre por la misma vocal, una característica que es interpretada por la mayoría de los investigadores como una redundancia de los signos silábicos, mientras que otros lo ven como un alfabeto redundante.

Las inscripciones del sudoeste tienden a escribirse en escritura continua, independientemente de la longitud del texto. Solo en algunos casos se utilizan separadores en forma de una barra vertical, como en la inscripción BDH FAR.06.02 de Mestras.

Hay 15 signos con valores consensuados (fig. 15): las cinco vocales a $(A)$, e $(\mathrm{O}), \mathbf{i}\left({ }^{(}\right)$, o (キ), u (니), las dos sibilantes, s (丰) y ś (M), las consonantes $\mathbf{l}(1), \mathbf{n}(\)$ y $\mathbf{r}\left({ }^{9}\right)$, los signos silábicos velares ka $(\bigwedge)$ y ke $(\supset)$, los signos silábicos dentales ta $(X)$ y ti $(\mathbb{(})$, y los signos silábicos labiales pa $(\xi)$ y pe $(\bigcirc)$.

La fig. 16 sintetiza las diferentes propuestas de interpretación para los caracteres más conflictivos. En las filas inferiores de la tabla figuran los siete signos, to $(A)$, tu $(\Delta)$, ki $(\Phi)$, ko $(\bowtie)$, te $(\forall)$, po $(\square)$ y ŕ $(W)$, para los cuales, a pesar de que no hay un valor de consenso, una de las propuestas ha recibido una gran mayoría de los apoyos, mientras que en las filas superiores de la tabla figuran los ocho signos más conflictivos: pu (目), ku (®), S81 (এ), S41 (导), S83 $\left(\Upsilon^{\top}\right)$, S80 (\), pi $(\uparrow)$ y el par S87 (\)-S92 (〔).

3 Véase la aportación de E. Luján en este mismo volumen. 


\begin{tabular}{|c|c|c|c|c|c|c|c|c|}
\hline & & $?$ & $\mathrm{~g} / \mathrm{k}$ & $b / p$ & $\mathrm{~d} / \mathrm{t}$ & & & \\
\hline a & $A$ & ${ }_{A} \mathbb{y}$ & ${ }_{A} \bigwedge$ & $\left.{ }_{A}\right\}$ & & $S$ & 丰 & 11 \\
\hline e & 0 & & | & 0 & 。 & '́s & $M$ & $?$ \\
\hline $\mathrm{i}$ & 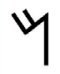 & & $\phi$ & $\uparrow$ & (1) & $\dot{r}$ & $r$ & $\downarrow$ Y \\
\hline 0 & $\neq$ & & $\neq \infty$ & ${ }_{*} \square$ & ${ }_{\neq} \Lambda$ & $r$ & 9 & VW H \\
\hline $\mathrm{u}$ & 4 & $\underset{4}{N}$ & ${ }_{4} \mathrm{WH}$ & 味 & ${ }_{4} \triangle$ & $\mathrm{n}$ & 4 & $8 \Phi \nu$ \\
\hline
\end{tabular}

Fig. 15. Signario de la escritura del sudoeste.

\begin{tabular}{|c|c|c|c|c|c|c|c|c|}
\hline Sign & Ref. & JU & JdH & JAC & VHC & JRR & MV & JFJ \\
\hline T & S83 & $\mathbf{n}(\mathbf{n})$ & $?$ & m? & $\mathbf{m}$ & $\mathbf{m}$ & $\mathbf{n}$ & ¿? \\
\hline$M$ & S80 & $\mathbf{m}$ & $-\mathbf{u} / \dot{s}$ & $-\mathbf{u}$ & $\dot{\mathbf{s}}$ & m & ś & $-\mathbf{u}$ \\
\hline $\mathbb{y}$ & S41 & $-\mathbf{a}$ & $?$ & $-\mathbf{a}$ & $\mathbf{h}$ & $\mathbf{h}$ & $\mathbf{f}$ & $-\mathbf{a}$ \\
\hline $0, D$ & S81 & pe? & ke & $?$ & $?$ & ke & r? & ? / ke? \\
\hline E & S47g & ku & $?$ & ku & te & pu & pu & pu \\
\hline 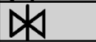 & S58 & pu & $?$ & pu & ko/ku & ku & ku & ku \\
\hline$\uparrow$ & S44 & $-\mathbf{i}$ & pi & $?$ & pi & pi & $?$ & pi \\
\hline$\Psi$ & S87/S92 & ti? & pi & $?$ & pi & pi & $?$ & -i? \\
\hline A & S57 & to & to/tu & to & to/tu & to & to & to \\
\hline$\Delta$ & G23 & tu & tu & tu & to/tu & tu & tu & tu \\
\hline$\Phi$ & S46 & $-\mathbf{i}$ & ki & ki & ki & ki & $\mathbf{k i}$ & ki \\
\hline$\bowtie$ & G17 & ko & ko & ko & ko/ku & ko & ko & ko \\
\hline E & S47f & te & te & te & te & te & $?$ & te \\
\hline$\square$ & S47a & po & po/pu & po & po/pu & po & po & po \\
\hline$y$ & S56 & $\dot{\mathbf{r}}$ & $?$ & $\mathbf{r}$ & $\mathbf{r}$ & $\dot{\mathbf{r}}$ & $\dot{\mathbf{r}}$ & $\dot{\mathbf{r}}$ \\
\hline
\end{tabular}

Fig. 16. Valores más controvertidos de la escritura del sudoeste: MLH IV [JU]; De Hoz 2010 [JdH]; Correa 1996 [JAC]; Correia 1996; 2014 [VHC]; Rodríguez Ramos 2000; 2015 [JRR]; Valério 2008; 2016 [MV]; Ferrer 2016 [JFJ].

Hay un grupo de signos similares con la forma de una $\mathrm{H}$ con múltiples barras horizontales que siempre aparecen delante de una vocal excepto la vocal i: S47b (口), S47c (日), S47d (目), S47e (目), S47h (目), S47i (目), S47j (目) y S86 (A). Estos signos generalmente se consideran variantes de bo $(\square)$, te $(\sharp)$ y bu (肘), dependiendo de la vocal anterior, $\mathbf{o}(‡), \mathbf{e}(\mathrm{O})$ o u $(4)$; aunque algunas variantes tienden a clasificarse entre los signos hápax o entre los signos con valor desconocido. La variabilidad de las formas podría tener una explicación geográfica, ya que el comportamiento parece más estable en el área nuclear 
de la escritura del sudoeste y más variable en la periferia, como ha observado Correa (1987, 279). Finalmente, Rodríguez Ramos (2000, 41) considera que cuando uno de estos signos en forma de $\mathrm{H}$ aparece antes de la vocal a $(A)$ podría corresponder a una variante de te $(\sharp)$ utilizada para representar el valor ta $(+)$.

En esta escritura también hay un alto número de signos que solo se certifican una vez y, por lo tanto, son difíciles de interpretar. Sin embargo, algunos de ellos corresponden a inscripciones conocidas exclusivamente por dibujos (BDH BEJ.06.04 / $\Lambda / Y$ ) o en mal estado (BDH BEJ.03.01 / $\lambda$ y BDH FAR.03.03 / W). Para casi todos se ha propuesto una interpretación como variantes de los signos más frecuentes y, en algunos casos, incluso como errores o meras decoraciones. Los siguientes son los más notables: 4 (BDH FAR.04.01; Guerra 2002), 8 (BDH FAR.03.02), $\$$ (BDH FAR.06.01), 扸 (BDH FAR.06.02), (BDH BEJ.04.12), 党 (Guerra 2009), $\longrightarrow$ (BDH BEJ.06.05), $\mathbb{V}$ (BDH FAR.02.01) y Y (BDH BEJ.01.01).

También debe tenerse en cuenta que el idioma de estas inscripciones es desconocido y, por lo tanto, las convenciones sobre el idioma ibérico, utilizadas también para la escritura ibérica suroriental, no son necesariamente válidas para la transcripción de la escritura del sudoeste. En particular, esto afecta a la transcripción de las vibrantes $\mathbf{r}$ ( $(9) / \dot{\mathbf{r}}(h)$, que intercambian sus valores, ya que $\mathbf{r}$ es el más frecuente, y a la transcripción de los signos labiales, ya que no se puede descartar la existencia de la sorda /p/. En cuanto a las diferencias entre la escritura del sudoeste y la ibérica suroriental, las más notables son las siguientes: el signo suroriental ba ( (\urcorner$)$ se interpreta principalmente con el valor pe en la escritura del sudoeste, donde aparece principalmente con la forma $\bigcirc$. El signo S42 (乡), cuyo valor es incierto en la escritura ibérica suroriental, se interpreta como pa en la escritura sudoeste. El signo S41 (\$), que se interpreta como be en la escritura ibérica suroriental, no tiene un valor de consenso en la escritura sudoeste, aunque podría tener una naturaleza silábica asociada a la vocal a. Además, hay algunos signos que no están documentados en la escritura ibérica suroriental: el signo to $(\AA)$, el signo $S 80\left({ }^{\wedge}\right)$, probablemente un silabograma asociado a la vocal $\mathbf{u}$, el signo $S 83(\mathbb{T})$, que es un signo común de la escritura ibérica nororiental con el valor de $/ \mathrm{m} /$, y los signos $\mathrm{S} 92$ (〈) y S87 ( $(\longleftarrow)$, que podrían ser variantes del mismo signo, probablemente un silabograma asociado a la vocal $\mathbf{i}$.

Finalmente, hay que señalar que los análisis paleográficos confirman la ausencia de un sistema dual en la escritura del sudoeste. Las variantes 
elegidas son casi siempre las simples, y cuando, en algunos casos raros, presentan un trazo adicional, el cambio de la vocal asociada confirma que en realidad podrían corresponder a un signo diferente: por ejemplo, ku $(\bowtie)$ / ko $(\bowtie)$ y to $(A) /$ tu $(\Delta)$. Este hecho es significativo para la genealogía de los sistemas de escritura paleohispánicos, ya que la presencia de un sistema dual en las dos escrituras ibéricas sugiere que su ancestro común también tenía que ser dual. Esto implicaría, entonces, que este antepasado no puede coincidir ni con la escritura del sudoeste ni con la escritura de Espanca, que tampoco es dual, como se describe en la siguiente sección.

\subsection{La escritura de Espanca}

El doble abecedario de Espanca se atestigua en una pequeña placa de esquisto encontrada en 1989 y consiste en dos abecedarios aparentemente idénticos de 27 signos cada uno (fig. 18.1). Algunos de los signos del primero, que se interpreta como el modelo, están incompletos en su parte superior y algunos de los signos del segundo, interpretado como la copia, están grabados con menor fuerza y precisión y son difíciles de identificar.

La característica más relevante del abecedario de Espanca (fig. 17) es el orden de los signos, que reproduce el orden relativo del alfabeto fenicio para sus trece primeros signos (Correa 1993; Adiego 1993; De Hoz 1996; MLH IV). Dado que el orden de los signos en el abecedario es una característica muy conservadora, esta coincidencia se ha tomado como una prueba del origen fenicio

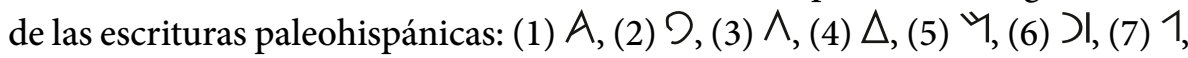

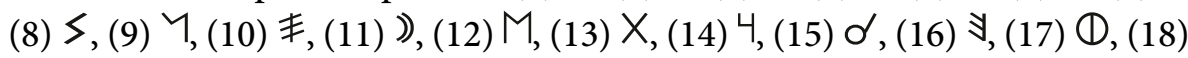

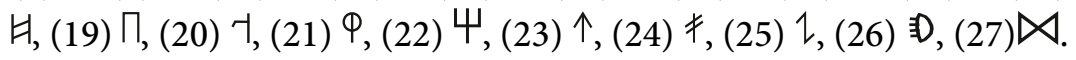

Hasta hace poco el abecedario de Espanca era el único abecedario paleohispánico existente, no obstante, en los últimos años se han descubierto una docena de abecedarios ibéricos nororientales (figs. 6, 8 y 10) que presentan diferentes tipos de ordenación, pero ninguno de ellos coincide con el orden atestiguado en el de Espanca.

A pesar de que la placa de Espanca se encontró en el mismo territorio donde se atestigua la escritura del sudoeste, parece estar más cerca de la escritura ibérica suroriental. En todo caso, para la mayoría de sus signos es posible encontrar una correspondencia clara con los signos surorientales y los sudoccidentales con el mismo valor en ambas escrituras. Por lo tanto, a pesar de las ligeras diferencias en las formas de algunos, es plausible suponer que también tienen este mismo valor en la escritura de Espanca. Sería el caso 


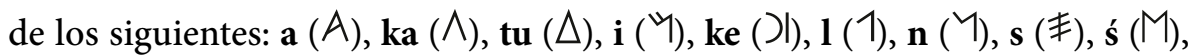

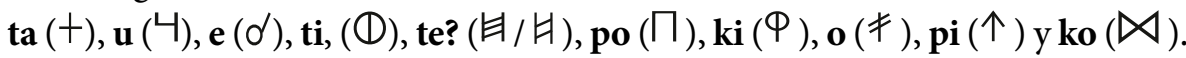

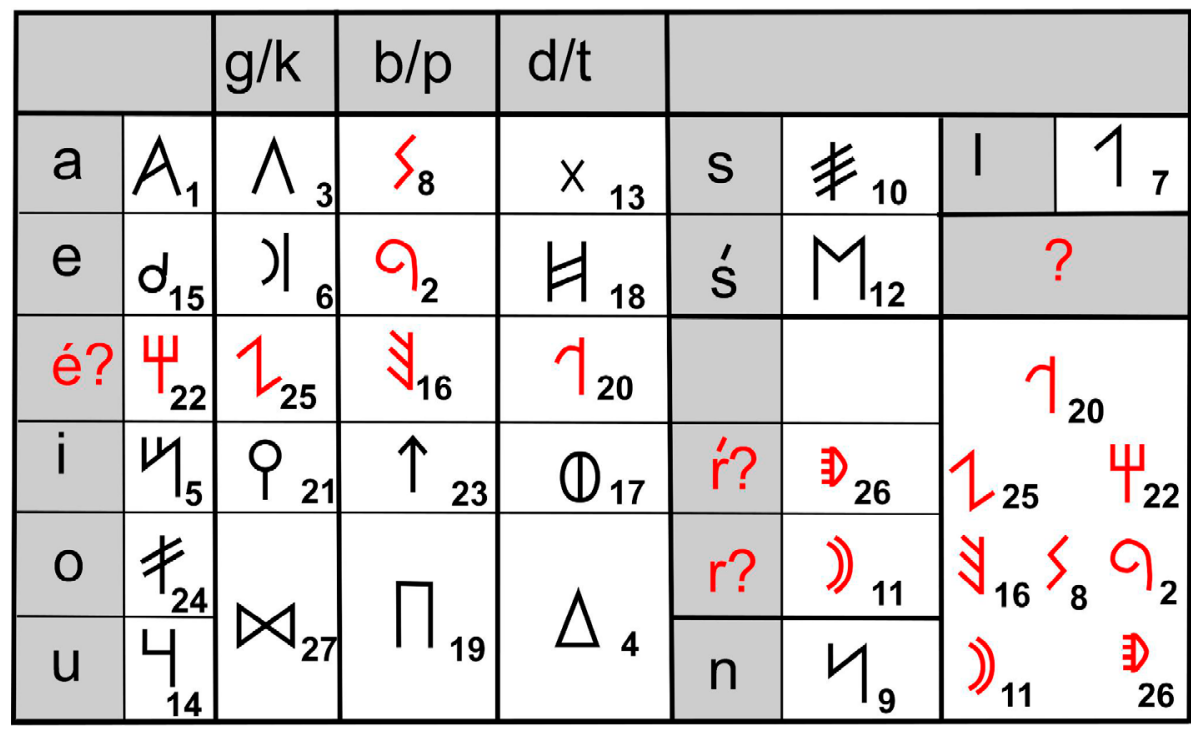

Fig. 17. Signario de la escritura de Espanca.

Las ausencias más notables en el abecedario de Espanca son los signos del sudoeste $\mathbf{k u}(\bowtie)$ y to $(\bowtie)$. También es probable que sea el caso del signo bu ( $($ \#), si el signo 18 (目 $\mathrm{O}$ 月), es en realidad una variante del signo te $($ A). Estas tres ausencias sugieren que en la escritura de Espanca las vocales o (₹) y $\mathbf{u}($ 니) podrían haber compartido los mismos signos silábicos: po/pu $(П) \mathbf{k o} / \mathbf{k u}(\bowtie)$ y to/tu $(\Delta)$. En cambio, la ausencia de los signos $\mathbf{r}(9)$ y ŕ $(W)$ es solo aparente, ya que podrían estar ocultos respectivamente en el signo ( ()$)$, considerando su posición, y en el signo 26, (D), considerando su forma. Sin embargo, el valor de este último signo no tiene por qué ser necesariamente ŕ en esta escritura. El signo conflictivo $S 81(\checkmark)$, común tanto a la escritura suroriental como a la del sudoeste, también está ausente en el abecedario de Espanca.

Hay algunos signos de Espanca que solo tienen equivalentes en una de las otras dos escrituras meridionales: tal es el caso del signo $(\Psi)$, y probablemente también del signo $25(1)$, aunque podría aparecer en la escritura del sudoeste en el hápax de la inscripción BDH BEJ.06.05 $(\vec{\nabla})$. Del mismo modo, es plausible el caso del dudoso vigésimo signo $(\neg)$, que podría ser el equivalente del signo M en la escritura sudoeste. 
Finalmente, hay tres signos en el abecedario de Espanca conocidos en ambas escrituras meridionales, pero con valores diferentes. Por lo tanto, su valor dependerá de cuál es el modelo correcto. Siguiendo la escritura del sudoeste, el signo 7 tendría el valor pe, mientras que el signo $\mathbb{\forall}$, aunque no tiene un valor de consenso, podría ser un signo silábico de una nueva serie silábica asociada a la vocal a, y el signo ' podría tener el signo valor pa. En cambio, siguiendo la escritura suroriental, el signo 7 podría tener el valor pa, el signo $\$$ podría tener el valor pe, y el signo \, a pesar de que no tiene un valor de consenso, podría ser un signo silábico labial asociado a la hipotética sexta vocal.

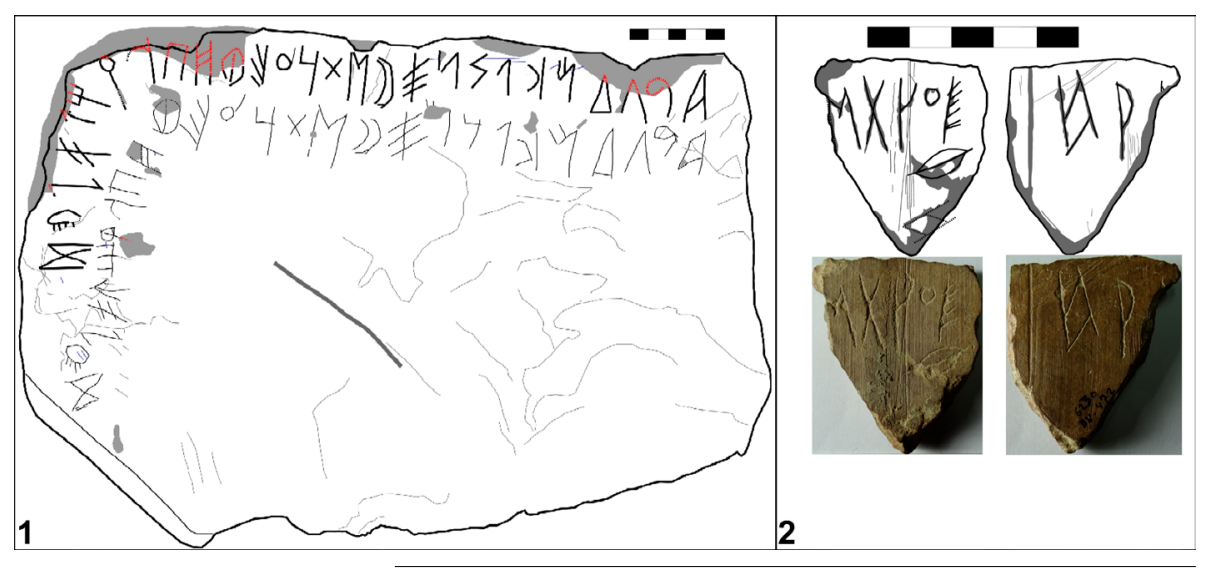

Fig. 18. El abecedario de Espanca y el de Villasviejas de Tamuja.

\subsection{Escrituras meridionales no identificadas}

Las inscripciones meridionales no identificadas son muy escasas y diversas desde el punto de vista paleográfico, soportes, origen geográfico y cronología. Como ya se ha dicho, además de las inscripciones que están claramente identificadas como ibéricas surorientales y del sudoeste, hay otros textos que probablemente pertenecen a otras escrituras diferentes. En primer lugar, debe recordarse que no es absolutamente seguro que todas las inscripciones generalmente clasificadas como ibéricas surorientales sean ibéricas, especialmente las más occidentales, ya que los límites de los territorios de habla ibérica no están perfectamente delimitados. Además, hay otras inscripciones, menos de veinte, que se encuentran claramente fuera del territorio ibérico en Andalucía, Extremadura y Portugal, con una cronología amplia que abarca desde el siglo VII a. C. hasta el siglo II a. C. 
La inscripción más interesante de este grupo es el óstracon de Villasviejas del Tamuja (Botija, Cáceres), que está inscrito en ambos lados (fig. 18.2). El texto en uno de los lados ha sido identificado recientemente como un abecedario meridional (Ferrer 2017b), ya que coincide exactamente con los siete signos que se muestran en la secuencia central del abecedario de Espanca (fig. 18). Aunque esta inscripción se encontró en 1976, los errores en la lectura propuesta no permitieron identificar esta inscripción fragmentaria como un fragmento de abecedario, cuando algunos años más tarde, en 1987, se encontró el abecedario de Espanca. Por otro lado, la inscripción en el otro lado del óstracon no es parte del abecedario, pero la presencia de la vibrante $\mathbf{r}\left({ }^{9}\right)$ en este texto, y plausiblemente también en la parte perdida del abecedario, introduce una nueva característica en relación con el abecedario de Espanca, donde este signo no puede ser claramente identificado, aunque podría estar representado por el signo 11. Al igual que con la inscripción de Espanca, la falta de dualismos diferencia esta escritura de la escritura dual ibérica suroriental, y la falta de redundancia lo diferencia de la escritura del sudoeste. Finalmente, este nuevo abecedario confirma el orden canónico de los abecedarios meridionales, siguiendo el orden heredado de la escritura fenicia, que contrasta con el orden variable y diferenciado de los abecedarios ibéricos nororientales.

\section{Principales problemas actuales y retos para el futuro}

Los principales problemas en el estudio de las escrituras epicóricas paleohispánicas están relacionados con el desciframiento, que en nuestro caso es una tarea continua, puesto que la solución a problemas que los investigadores que nos precedieron dejaron abiertas no hace más que abrir nuevas incógnitas que probablemente requerirán de la aparición de nuevas inscripciones, y quizás de nuevos investigadores, para ser solucionadas.

También está pendiente la normalización y puesta al día del sistema de transcripción de la escritura epicórica en caracteres del alfabeto latino. Algunas de las convenciones de transcripción tradicionales no parecen ya las más adecuadas de acuerdo con los conocimientos actuales, pero por tradición las seguimos empleando. Adicionalmente, la aparición de nuevos signos y variantes duales ha requerido definir sobre la marcha nuevas convenciones que quizás habría que repensar globalmente y normalizar.

Finalmente, la digitalización de los corpus de inscripciones en bases de datos epigráficas requiere disponer de herramientas que permitan representar 
adecuadamente las diferentes variantes de escritura. Para dar solución a este reto hay dos tareas en marcha. Por una parte, es necesario disponer de una codificación Unicode, que permita la definición de un corpus de signos base aceptada por la comunidad tecnológica internacional. Y por otra, es necesario actualizar y unificar las diferentes clasificaciones de variantes de signos y plasmar el resultado en una fuente específica que facilite los análisis paleográficos de los especialistas.

\subsection{Problemas de desciframiento}

Como se ha descrito en los apartados anteriores, las escrituras paleohispánicas distan de estar descifradas; incluso la mejor conocida, la escritura ibérica nororiental aún contiene numerosos aspectos pendientes de resolver, la mayoría relacionados con el alcance real del sistema dual. En la familia meridional los enigmas son de mucho mayor calado, puesto que aún hay muchos signos sin valor de consenso, escrituras pendientes de definir y también problemas relacionados con el alcance real del sistema dual. También el modelo genealógico que explica la génesis de las dos familias y el desarrollo de las diferentes escrituras de cada familia presenta aún múltiples incógnitas. A continuación, se detallan algunos de los principales problemas y las líneas de investigación que intentan resolverlos.

\subsubsection{Identificar la oposición fonética que se oculta detrás de las oposiciones gráficas de los diferentes sistemas duales}

La justificación del valor de las dualidades en las oclusivas dentales y velares, que permiten diferenciar las sordas de las sonoras, marcando la sorda en la escritura ibérica nororiental y la sonora en la suroriental, es relativamente clara por los paralelos en inscripciones latinas, griegas y grecoibéricas. El resto de las oposiciones gráficas identificadas, tanto en la escritura dual ampliada, como en la escritura dual suroriental, generan aún dudas, aunque allí donde es posible se plantea como hipótesis por defecto que la finalidad de la distinción sea diferenciar los sonidos fortes de los lenes.

El sistema dual ibérico suroriental (Ferrer 2010) también tiene dualida-

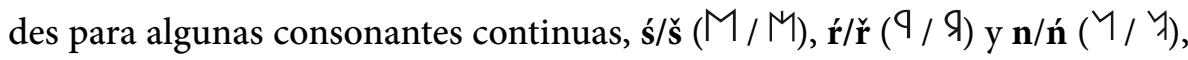
para las que, si el mecanismo funciona igual que en las oclusivas, la marcada correspondería a la sonora (lenis), mientras que la no marcada correspondería a la sorda (fortis). Así lo he supuesto en el caso de la sibilante, interpretando la marcada, como sonora š (M) y la no marcada, como sorda ś (M). No obstante, 
en el caso de la vibrante, la marcada, 亡̌ (Я) aparece casi siempre en posición intervocálica, por lo que parece más probable que represente a la múltiple (fortis), mientras que la no marcada representaría a la simple (lenis), ́r ( ${ }^{9}$ ). Algo parecido pasa con la nasal, puesto que los paralelos de los elementos que van con ń, con elementos nororientales que van con $\mathbf{m}\left(\Upsilon^{\aleph}\right)$, aconsejan considerar que la fortis fuese ń ( $(1)$ y la lenis, $\mathbf{n}(\bigvee)$.

Dualidades similares se detectan en las consonantes continuas de la escritura ibérica nororiental dual ampliada (Ferrer 2015), s/s $\left(\sum / \xi\right)$ y $\check{\mathbf{r}} / \mathbf{r}(P / \Phi)$, aunque se intercambian las sibilantes afectadas. Así, respecto de la sibilante, he propuesto siguiendo el modelo de las oclusivas nororientales, que la marcada, $\hat{\mathbf{s}}(\xi)$, fuese la sorda (fortis), mientras que la variante sin marcar, $\mathbf{s}(\zeta)$, fuese la sonora (lenis). No obstante, siguiendo el modelo de la vibrante suroriental y suponiendo inversión en el significado de la marca, he supuesto que la vibrante no marcada, $\check{\mathbf{r}}(\mathrm{Y})$ fuese la múltiple (fortis), mientras que la variante marcada, $\dot{\mathbf{r}}(\Phi)$, fuese la simple (lenis). Probablemente, el signo $\mathbf{m}$ actuara en la escritura ibérica dual como variante marcada de $\mathbf{n}\left(Y^{2}\right)$, para distinguir la fortis de la lenis. Aunque en el cuadro siguiente se ha representado en la celda que le corresponde según su transcripción, tanto para el sigo ś nororiental como para el sigo s suroriental, que no aparecen formando dualidad, cabe suponer que podrían representar a sus equivalentes en su otra escritura, tanto sordos como sonoros.

\begin{tabular}{|c|c|c|c|c|}
\hline \multicolumn{5}{|c|}{ Sibilantes ibéricas } \\
\hline $\begin{array}{c}\text { Punto de } \\
\text { articulación }\end{array}$ & \multicolumn{2}{|r|}{ fortis } & \multicolumn{2}{|r|}{ lenis } \\
\hline S1 & sorda & $s(M / M)$ & sonora & š (M - sólo suroriental) \\
\hline S2 & sorda & $\hat{\mathbf{s}}(\xi$ - sólo nororiental) & sonora & s(く/丰) \\
\hline
\end{tabular}

\begin{tabular}{|c|c|c|}
\hline \multicolumn{3}{|c|}{ Vibrantes ibéricas } \\
\hline Punto de articulación & vibrante simple (lenis) & vibrante múltiple (fortis) \\
\hline $\mathrm{V} 1$ & $\dot{\mathbf{r}}(\Phi, 9)$ & $\check{\mathbf{r}}(\mathrm{P} / \mathrm{l})$ \\
\hline $\mathrm{V} 2$ & $\mathbf{r}(0 / \mathrm{K})$ & \\
\hline
\end{tabular}

\begin{tabular}{|c|c|c|}
\hline \multicolumn{3}{|c|}{ Nasales ibéricas } \\
\hline Punto de articulación & fortis & lenis \\
\hline N1 & ń $\left(\mathbf{m}\right.$ ? $\left.^{\top}, \eta\right)$ & $\mathbf{n}(\nearrow, \bigvee)$ \\
\hline
\end{tabular}


Por lo que respecta a las dualidades de las vocales, en la escritura nororiental dual ampliada, a/á (D/P), e/é ( $(E / E), \mathbf{i} / \mathbf{i}(N / N)$, o/ó ( H/A) y u/ú ( $/$ / $)$ ), hasta ahora no ha sido posible encontrar una explicación fonética plausible para justificar esta oposición gráfica entre las vocales marcadas y las no marcadas. La nueva dualidad detectada en la escritura turdetana que afectaría a la lateral podría seguir el mismo esquema de tipo meridional de diferenciar la marcada (lenis) de la no marcada (fortis).

\subsubsection{Nuevas variantes de escritura dual y trial en la escritura ibérica nororiental}

La clasificación de las escrituras duales nororientales en duales ampliadas y duales estándar es probablemente una simplificación de una realidad más compleja. La individualización de estas dos escrituras está asegurada por los abecedarios conocidos actualmente, pero hay algunas evidencias que apuntan a la existencia de otras variantes de escrituras duales nororientales con características mixtas. Sería el caso de algunas inscripciones largas del tipo dual estándar, por ejemplo, la lámina de plomo de Ullastret (BDH GI.15.05) y la de Castelló (BDH CS.14.01), que muestran el uso simultáneo de dos variantes de ŕ $(\mathrm{Q} / \Phi)$, que es una característica de los abecedarios duales ampliados.

Además, algunas inscripciones largas duales muestran el uso simultáneo de tres variantes del signo ke. Es el caso de la lámina de plomo de Castelló (BDH CS.14.01) donde coexiste un ke (E) de dos trazos, con variantes de un solo trazo $(\mathcal{C})$ y con variantes no marcadas $(C)$. De manera similar, en la lámina de plomo de Ensérune (BDH HER.02.373) una variante con puntos del signo ke $(C)$, coexiste con una variante con un solo punto $(C)$ y con una variante no marcada $(C)$. Este comportamiento también se puede observar en la lámina de plomo de Los Villares (BDH V.07.02), donde se usan tres variantes simultáneas del signo ka $(\mathrm{A} / \mathrm{A} / \mathrm{A})$. Este comportamiento podría ser un indicio de que la variabilidad de tres elementos también podría ser internamente significativa, al menos para algunos signos en algunas variantes de escritura (Ferrer 2017a; 2018a; 2019; Ferrer y Moncunill 2019).

\subsubsection{La posible sexta vocal de la escritura ibérica suroriental}

La escritura ibérica suroriental podría presentar la especificidad de tener una sexta serie vocálica; Javier de Hoz $(1993 b ; 2011)$ ha postulado una serie con un sonido vocal similar a /i/, que transcribe con el diacrítico í. Su existencia implicaría los dobletes de signos silábicos con esta vocal: í (У) / i ( (\): tí (Ө) / ti 
(Ч), kí (9) / ki ( ( ), bí ( $\uparrow) /$ bi (า). Sin embargo, esta interpretación no ha encontrado muchos apoyos, ya que el resto de los investigadores consideran que los signos interpretados en esta propuesta como ti, ki y bi tienen claramente otros valores que permiten establecer claros paralelos entre segmentos ibéricos nororientales y surorientales.

Una formulación alternativa de esta hipótesis considera la posibilidad de que haya existido una sexta vocal, pero representada por el signo S48 ( 4$)(\mathrm{Fe}-$ rrer 2010a, 72). Este signo ya había sido interpretado previamente por otros investigadores (fig. 14) como una vocal que podría coincidir con e. Esta serie vocal podría estar constituida por los signos S81 ( (), con el valor dental, S45 $(\mathcal{Z})$, con el valor velar, y $S 42(3)$, con el valor labial.

\subsubsection{Los silabogramas de las vocales o/u en las escrituras meri- dionales}

Las dificultades para identificar los signos silábicos correspondientes a los valores $\mathbf{k u}$, to y bu en la escritura ibérica suroriental contrastan con la clara identificación de los signos ko $(\bowtie)$, tu $(\Delta)$ y bo $(\square)$. El contraste se acentúa en la escritura del sudoeste, puesto que, en este caso y gracias a la redundancia vocálica, tanto los signos para ko $(\bowtie)$, tu $(\triangle)$ y bo $(\square)$, como los signos para ku $(\bowtie)$, to $(A)$ y pu $(\vDash)$ son muy claros. En cambio, el abecedario de Espanca confirma la ausencia de los signos problemáticos no documentados en la escritura ibérica suroriental: $\mathbf{k u}(\bowtie)$, to $(৯)$ y pu $(\vDash)$, en este último caso suponiendo que el signo escaliforme documentado, independientemente del número de trazos, es te.

Una posible explicación de este comportamiento es que la escritura original meridional las vocales o ( $₹$ ) y $\mathbf{u}($ 니) hubiesen compartido los signos silábicos, circunstancia que sería la recogida por el abecedario de Espanca. Posteriormente, la escritura suroriental y la del sudoeste habrían adoptado diferentes soluciones, pero que en ambos casos pasarían por desdoblar el signo existente modificando ligeramente el signo original. En este sentido el comportamiento de la escritura del sudoeste es el más claro, puesto que parece evidente la relación entre los signos $\mathbf{k u}\left(\aleph^{(}\right)$, to $($A $)$y pu $($目) y los originales ko $(\bowtie)$, tu $(\Delta)$ y bo $(\square)$. En el caso de la escritura ibérica suroriental es mucho menos evidente, pero podría encajar en este mecanismo el signo hápax $\bowtie$ (BDH V.17.02), que se usa en un contexto en el que representa plausiblemente el valor ku. También podría ser el caso del signo li', que se utiliza en un contexto en el que es plausible para bu, aunque también podría encajar como 
variable compleja del signo bo en el contexto de la escritura turdetana (Ferrer e. p.a). Incluso ambas opciones podrían ser correctas y en el contexto de una escritura no dual que procede de una dual, algunas variantes duales obsoletas podrían haber sido reconvertidas para representar los nuevos valores. Sea como sea, cualquiera de estas explicaciones no puede considerarse como definitiva, ya que el número de signos sin valores consensuados en las escrituras meridionales todavía es muy alto.

\subsubsection{La escritura turdetana}

El análisis probabilístico certifica que el signo S65 $(\widehat{\vartheta})$ que aparece en la tapadera de plomo de Piquía (Arjona, Jaén) y las láminas de plomo de La Mesa (Alcolea del Río, Sevilla), Barranco del Rey (Gádor, Almería) y Los Allozos (Montejícar, Granada), es una variante del signo a ( $A$ ) (Ferrer 2018b). Su distribución geográfica lo convierte en un buen marcador de una de las escuelas epigráficas turdetanas y permite empezar a definir esta escritura en base a las cuatro inscripciones que la usan y a otras de esta zona que no puedan ser atribuidas con seguridad a la ibérica suroriental y a la del sudoeste, como las leyendas monetales de Obulco y Salacia (Alcácer do Sal, Setúbal, Portugal) y el relieve de Cerro Boyero (Córdoba).

Por otro lado, la toponimia y la antroponimia turdetana certifican la existencia en la lengua turdetana de oposición de sonoridad en las oclusivas, también en las labiales, Iponoba, y la existencia de sonidos especiales que se representan en latín mediante signos geminados, tanto en las oclusivas sordas, Baesippo, Attenius, Broccus, como en las consonantes continuas, Sisanna, Ossonoba, Antullus, Carruca. También se detecta la presencia de aspiración ante vocal, Hasta, y de consonantes aspiradas, casi siempre velares sordas, Culchas. Esta variedad de fonemas requeriría a la escritura paleohispánica que expresase esta lengua una complejidad que podría implementarse con marcas adicionales sobre los signos base y mediante nuevos signos.

$\mathrm{Al}$ menos parcialmente, las particularidades de la lengua turdetana podrían encajar con las características que presentan las inscripciones turdetanas, con signos especiales ( $\underset{\aleph}{*}$ y), de valor aún no del todo claro, múltiples signos marcados, a veces con doble marca, como el signo ka (A) de Piquía, quizás para representar la oclusiva velar geminada o la aspirada, e incluso alguna dualidad explícita en la serie labial, tal como se esperaría de una lengua que distingue labiales sordas de sonoras, como la del signo ba $(\gg / \gamma)$ en Los 
Allozos, circunstancia relevante, ya que esta oposición no se detecta ni en la escritura ibérica nororiental dual, ni en la suroriental dual.

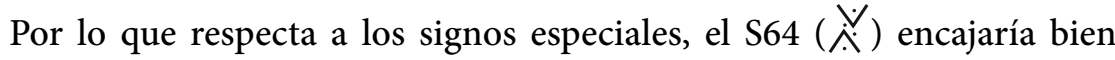
como signo consonántico, quizás una segunda vibrante, como ya se ha propuesto (Faria 1990-1991, 76; Rodríguez Ramos 2006, 35), o su equivalente formal con otro valor. Mientras que el signo $\mathcal{R}_{\mathrm{R}}$ encajaría mejor como signo silábico, quizás una variante (super)compleja de ba $(7)$ u otro valor.

No obstante, la escasez de inscripciones y su escasa longitud impiden profundizar en el análisis realizado. Entre los problemas detectados, cabe destacar que no se han documentado aún las variantes complejas de signos silábicos relativamente frecuentes, ni tampoco dualidades explícitas de signos consonánticos frecuentes, como sería el caso de las vibrantes. Resta también por aclarar la existencia o no de una sexta vocal, que podría explicar la abundancia de signos en determinadas posiciones; y el problema de los silabogramas de las vocales $\mathbf{o}$ y $\mathbf{u}$, en los que algunos candidatos a variante compleja, también podrían ser el signo pendiente de identificar correspondiente a una de estas vocales. Aún no se ha definido el signario específico de esta escritura y los signos específicos de esta escritura aparecen dentro del cuadro correspondiente a la escritura ibérica suroriental (figs. 2 y 13).

En todo caso, el uso simultaneo en las leyendas monetales de Obulco de variantes simples y complejas para representar la misma leyenda, como sería

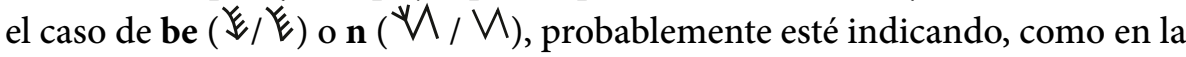
escritura nororiental dual, que el uso de las marcas en algún momento dejó de ser significativo, por lo que es posible que en algunas de las inscripciones analizadas los signos marcados fuesen solo el testimonio de una tradición ya perdida o en proceso de desaparición.

Por lo que respecta a la posición de la escritura turdetana en el modelo genealógico, parece plausible considerar que esta escritura fuese el modelo a partir del cual se desarrolló la escritura ibérica suroriental, teniendo en cuenta que la ruta de difusión tuvo que ser el Guadalquivir. También es plausible considerar, por la complejidad que se intuye en el uso de los signos marcados, que la escritura turdetana quizás fuese también la propia escritura meridional original, a partir de la cual se habrían desarrollado el resto de las escrituras meridionales (Ferrer e. p.a). 


\subsubsection{La cuarta serie silábica de la escritura del sudoeste}

El comportamiento redundante de la escritura del sudoeste se puede expresar por medio de una matriz (fig. 19) que ayuda a mostrar todas las formas posibles en que se pueden emparejar los signos (Ferrer 2016). Esto permite calcular la ratio de fidelidad (RF) de un signo, cuantificando cuán redundante es. Este comportamiento combinatorio diferencia claramente tres grupos de signos, que podrían clasificarse respectivamente como silábicos ( $\mathrm{S} 1, \mathrm{~S} 2, \mathrm{~S} 3$ y S4), vocálicos (V) y consonánticos (C), casi sin tener en cuenta ninguna otra información. El caso extremo se refleja en los signos del área S1, ke (Pl), ti (D), to $(\triangle)$, ka $(\wedge)$ y ku $(\bowtie))$, todos suficientemente documentados, con más de cinco casos, presentando una ratio de fidelidad del $100 \%$, puesto que siempre se combinan con el mismo signo. Los signos del área S3, S92/S87 (\/向), S41 ( ) y S83 ( $(1)$ también tienen una ratio de fidelidad del 100\%; pero son menos frecuentes que los signos del área $S 1$. Los signos del área $S 2$, ta $(X)$, pa $(\xi)$, pe $(\bigcirc)$, ko $(\bowtie)$, pu $($ (l) $\mathbf{k i}(\Phi)$, tu $(\triangle)$ y po $(\square)$, presentan algunas excepciones a la regla (área $\mathrm{X}$ ), pero todavía tienen ratios de fidelidad superiores al $75 \%$. Finalmente, los signos del área $S 4$, pi $(\uparrow)$, te $(\sharp), S 81\left(\left(^{\prime}\right)\right.$ y el grupo de signos escaliformes, por ejemplo, S47e (目), se comportan como signos silábicos, pero con ratios de fidelidad más bajos debido a irregularidades específicas. La redundancia también hace que los signos $\mathbf{a}(A), \mathbf{e}(\mathrm{O}), \mathbf{i}\left({ }^{(}\right), \mathbf{o}\left(\right.$ (キ) y $\mathbf{u}$ ( $\left.^{(}\right)$sean los que tienen más posibilidades combinatorias, ya que los signos del primer grupo combinan casi exclusivamente con ellos. Un tercer grupo, ś (M), s ( $\mathbf{l}\left({ }^{1}\right) \mathbf{r}\left({ }^{(}\right)$y $\mathbf{n}($ ( ), solo se puede caracterizar porque sus elementos constitutivos no encajan en ninguno de los otros dos grupos.

Por lo tanto, con respecto a la estructura de esta escritura, está claro que hay más de 15 signos silábicos, pero solo cinco vocales, lo que significa que es necesario considerar la existencia de una serie silábica adicional, menos frecuente que las tres ya identificadas. velares, dentales y labiales. Hay dos candidatos claros que podrían pertenecer a esta nueva serie: el signo S41 ( $)$, que es probablemente un signo silábico asociado a la vocal a, y el signo S80 ( Y), probablemente un signo silábico asociado a la vocal $\mathbf{u}$. El resto de los signos silábicos de esta serie podrían esconderse entre algunos de los signos menos frecuentes y hápax, como los signos S92 (\) y S87 ( $)$, que podrían ser variantes del mismo signo, el signo silábico asociado a la vocal i de esta nueva serie, no obstante, la propuesta mayoritaria es considerarlos variantes del signo pi $(\uparrow)$. 


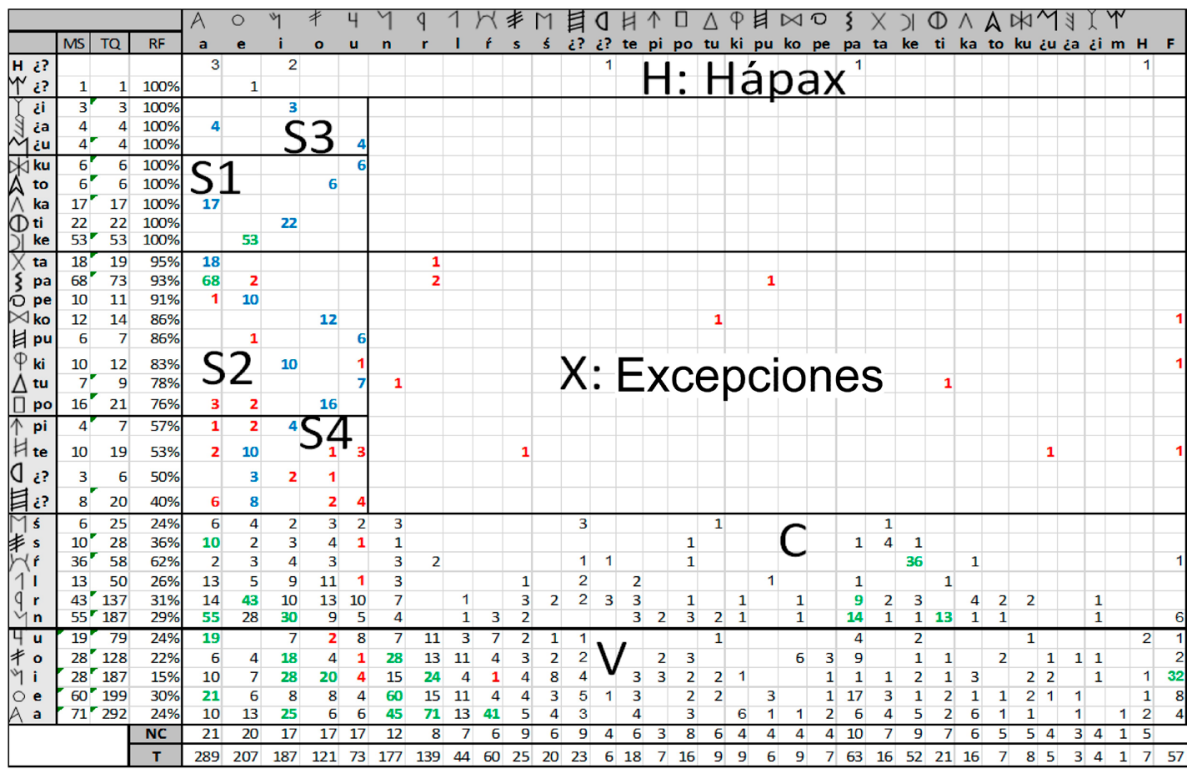

Fig. 19. Matriz combinatoria de la escritura del sudoeste.

\subsection{Problemas de transcripción y uso de diacríticos}

Por lo que respecta a la escritura ibérica nororiental, el ejemplo paradigmático de los problemas de transcripción es el signo nasal ḿ $(\bigvee)$ que normalmente genera secuencias ilegibles cuando va seguido de consonante. $\mathrm{Su}$ transcripción es la tradicional, derivada de su uso en la escritura celtibérica, donde actualmente se transcribe como n; pero que no funciona en la escritura ibérica, donde combina un componente nasal y un componente vocálico. Aunque ha habido diversas propuestas alternativas, ninguna ha conseguido imponerse.

Otro problema de transcripción pendiente de normalizar es el de las vibrantes que se transcriben como $\dot{\mathbf{r}}(\Phi)$ y $\mathbf{r}(\circlearrowleft)$ de forma inversa a la que naturalmente les correspondería, $\mathbf{r}(\Phi)$ y $\mathbf{r}(()$, puesto que la vibrante más frecuente es $\Phi$. De hecho, esta es la convención que se estableció en grecoibérico, donde el signo $\mathbf{r}\left(\nabla^{\prime}\right)$ es el que aparece con diacrítico. En celtibérico el problema desaparece, puesto que solo hay una vibrante $\mathbf{r}(\Phi)$, pero el cambio unificaría su transcripción. En la escritura ibérica suroriental el cambio de transcripción dejaría a 9 como $\mathbf{r}$ y a $W$ como ŕ, lo cual sería coherente con que $\uparrow$ sea la vibrante más frecuente y este sea el carácter para $\mathbf{r}$ en la escritura fenicia. Además, esta sería la notación que le correspondería a la vibrante 
más frecuente de la escritura del sudoeste $\mathbf{r}\left({ }^{9}\right)$, unificando la transcripción de las dos escrituras meridionales y quedando $\mathbf{r}(W)$, como segunda posible vibrante.

Otro signo de transcripción problemática es el signo $T$, que también aparece como $I$. Aunque se consideró inicialmente un alógrafo de $\mathbf{m}\left({ }^{\top}\right)$ o ḿ $(\bigvee)$, recientemente se ha confirmado como un signo autónomo, ya que aparece en diversos abecedarios junto con $\mathbf{m}\left({ }^{\aleph}\right)$ y $\mathbf{m}(\bigvee)$. Así pues, todo apunta a que se trata de otro signo nasal y es por ello por lo que inicialmente (Ferrer 2008) propuse representarlo con el signo m̀ con acento grave, aunque en trabajos posteriores he usado las formas $\mathrm{T} / \mathrm{I}$ por su parecido formal a la espera de una solución de consenso.

Otro signo poco frecuente y de transcripción problemática es el signo $\uparrow$, que normalmente se ha considerado una variante de e $(\llcorner), \mathbf{e} 7$, o ka $(\wedge)$, ka7. No obstante, aparece en el abecedario de Castellet de Bernabé detrás de la lateral 1 ( $\uparrow$ F) y en diversas inscripciones pintadas de Llíria aparece también siempre siguiendo a la lateral y coincidiendo con variantes estándar tanto de ka como de e. Como en algunos textos parece plausible suponer que tenía un componente vocálico, se representa arbitrariamente en este documento como â, en lugar de á, como se transcribe en otras obras, para evitar la confusión con la variante compleja de $\mathbf{a}$.

Otro signo para el que aún no existe una convención acordada para su transcripción es el signo similar a una espiga ( $\left.\Downarrow_{\mathrm{o}} \Downarrow\right)$, que a veces se transcribe como e $(E / E)$, aunque también podría ser una forma compleja del signo $\mathbf{u}(\uparrow)$, una variante de bo (*) o un signo distinto.

La transcripción de dualidades en las oclusivas en la escritura nororiental tiene dos modalidades principales: por un lado, la que transcribe las variantes marcadas como sordas (ta y ka, por ejemplo) y las no marcadas como sonoras (da y ga, por ejemplo), y de forma inversa en la escritura suroriental; y por otro, la que las transcribe diferenciando la marcada de la no marcada con un diacrítico sobre la vocal (tá / ta y ká / ka, por ejemplo). La aparición de trialidades ha obligado a buscar una alternativa para representar los tres valores que ha pasado por añadir un diacrítico a la velar sorda afectada: ḱa y ḱe.

La identificación de los nuevos sistemas duales ha complicado el panorama en la representación de las consonantes continuas, puesto que ha sido necesario duplicar transcripciones en signos que ya eran identificados con diacríticos, por lo que se ha optado por usar el circunflejo invertido (̌r) como 
sucedáneo de diacrítico doble allí donde era necesario, por ejemplo, para distinguir la dualidad de la vibrante $\mathbf{r}(\Phi)$. En el caso de las sibilantes el tema se complica, ya que el ibérico nororiental y el suroriental marcan una sibilante distinta, por lo que para poder distinguir las cuatro se ha optado por usar el circunflejo normal ( $\hat{\mathbf{s}})$. En el caso de las dualidades de las vocales, la solución adoptada ha sido añadir un diacrítico en forma de acento.

En las escrituras meridionales no se dispone de una transcripción acordada para muchos de los signos, por lo que las dos alternativas habituales son representarlos gráficamente o bien mediante un código arbitrario, normalmente siguiendo la codificación de De Hoz $(2010 ; 2011,740)$.

La representación de la redundancia en la escritura del sudoeste no es unánime: en algunos casos se indica la vocal entre paréntesis, ka(a), en otros como superíndice, $\mathbf{k}^{\mathbf{a}} \mathbf{a} \mathbf{y}$ en otros sin marca alguna, kaa.

\subsection{La codificación Unicode de las escrituras paleohispánicas}

El proyecto de codificación Unicode para las escrituras paleohispánicas está siendo desarrollado por un equipo de la Universidad de Barcelona del que formo parte, junto con Noemí Moncunill y Javier Velaza y que cuenta también con la colaboración de Deborah Anderson de la Universidad de Berkeley y de su equipo de trabajo. Tras múltiples intentos parece que la propuesta actual cuenta ya con el apoyo suficiente para ser aprobada (fig. 20). Aunque en algún momento del proceso se recomendó la unificación de todas las escrituras en una única codificación, finalmente se ha recuperado la propuesta original de codificación diferenciada para las escrituras meridionales y las nororientales (Ferrer et al. 2016).

El objetivo del equipo ha sido intentar reflejar al máximo las características distintivas de las diferentes escrituras paleohispánicas, siempre teniendo en cuenta que la codificación debía reflejar los signos que representaban fonemas distintos y no meras variantes formales. No se trataba de realizar la codificación de todas las variantes de signos, que es un proyecto paralelo que está en curso, sino de codificar el conjunto mínimo de signos distintivos. Aun contando con las dos codificaciones separadas, agrupar una escritura dual con su equivalente no dual significa perder los matices diferenciales de cada escritura y codificar la escritura que más variabilidad presente, que en el caso nororiental es la escritura ibérica dual ampliada. La escritura celtibérica no presenta problemas en este sentido, puesto que es un subconjunto de la ibérica, aunque con particularidades de transcripción. En el caso meridional, la 
suma final queda menos reconocible, puesto que las diferencias estructurales entre las diferentes escrituras meridionales son más acusadas que en el caso nororiental y el número de signos con valor desconocido es mucho mayor, diez meridionales, frente a uno nororiental. En todo caso, la posibilidad de definir fuentes específicas para cada escritura, o incluso para cada variante local, con los alógrafos específicos que las caracterizan, permitiría recuperar las particularidades de cada una de ellas.

Así pues, se han incluido codificaciones distintas para todas las posibles variantes duales propuestas e incluso para las trialidades más claras, como las de ka y ke, que están presentes en algunas inscripciones y requieren de codificaciones para los tres valores. Aunque el equipo técnico de Unicode ha recomendado codificar también con tres valores otros casos, como las trialidades de ti y to, para solucionar ambigüedades que se presentan al usuario actual, finalmente hemos decidido que prevaleciera el criterio estrictamente epigráfico y el punto de visto interno ibérico, puesto que en estos casos los tres valores no coinciden en ninguna inscripción y hay dudas razonables de que lo llegaran a hacer en la escritura ibérica nororiental, aunque quizás sí en alguno de sus antecesores, puesto que la distribución geográfica de la variante supercompleja de cuatro trazos y la simple de dos trazos es casi excluyente (Ferrer 2019).

Se ha limitado la codificación de los hápax de la escritura del sudoeste, puesto que probablemente, la mayoría acaben siendo variantes de los signos ya conocidos. No obstante, si se confirma la cuarta serie silábica, será necesario ampliar la codificación en al menos dos signos más, que muy probablemente se ocultan entre los hápax actuales.

Por lo que respecta a los signos más conflictivos del abecedario de Espanca, el signo $11($ ()) debería ser una variante formal de $\mathbf{r}(9)$, tanto por su posición en el abecedario (la que correspondería a r) como por los paralelos paleográficos, hay alguna variante nororiental muy similar en el elemento balkar de una inscripción rupestre (Ferrer 2019). Por lo tanto, no sería necesario codificarla por separado, no obstante Unicode sugiere incluirlo en la codificación. El mismo caso se da con el signo 26 (D), que paleográficamente corresponde a una evolución del signo ŕ $(W)$, no documentado en Espanca, aun cuando en este caso se ha aceptado la justificación de su no codificación. En el caso del signo 20 (7), el problema es que no es clara la forma del signo, puesto que está en una zona dañada del abecedario y además todo apunta a que se trate de una variante del signo $S 80(\mathcal{M})$, por lo que tampoco se contempla su codificación. 
Una de las últimas actualizaciones del modelo es la incorporación a la codificación de las últimas investigaciones sobre la escritura turdetana (Ferrer e. p.a) que obliga a considerar en la codificación de la escritura meridional la existencia de dualidades en las labiales y en la lateral. Y aunque no se documenta explícitamente, también se ha considerado la existencia la trialidad del signo ka meridional para dar visibilidad a la variante con doble trazo interior de la inscripción de Piquía, puesto que en el contexto meridional este testimonio es excepcional. También se incluye una posible trialidad para los signos nasales, teniendo en cuenta la existencia de variantes de signos nasales con múltiples marcas y la existencia en la toponimia y antroponimia turdetana de indicios de existencia de tres nasales representadas en escritura latina por $n, m$ y $n n$. No obstante, cabe considerar estas alternativas como meras propuestas de trabajo que se deberán ir revisando a medida que se disponga de un corpus mayor de inscripciones.

Fig. 19. Codificación Unicode de las escrituras paleohispánicas; propuesta de enero de 2020: <https://www.unicode.org/L2/L2020/20047north-palaeohispanic.pdf $>1$ $\leq$ https://www.unicode.org/L2/L2020/20048south-paleohispanic.pdf>

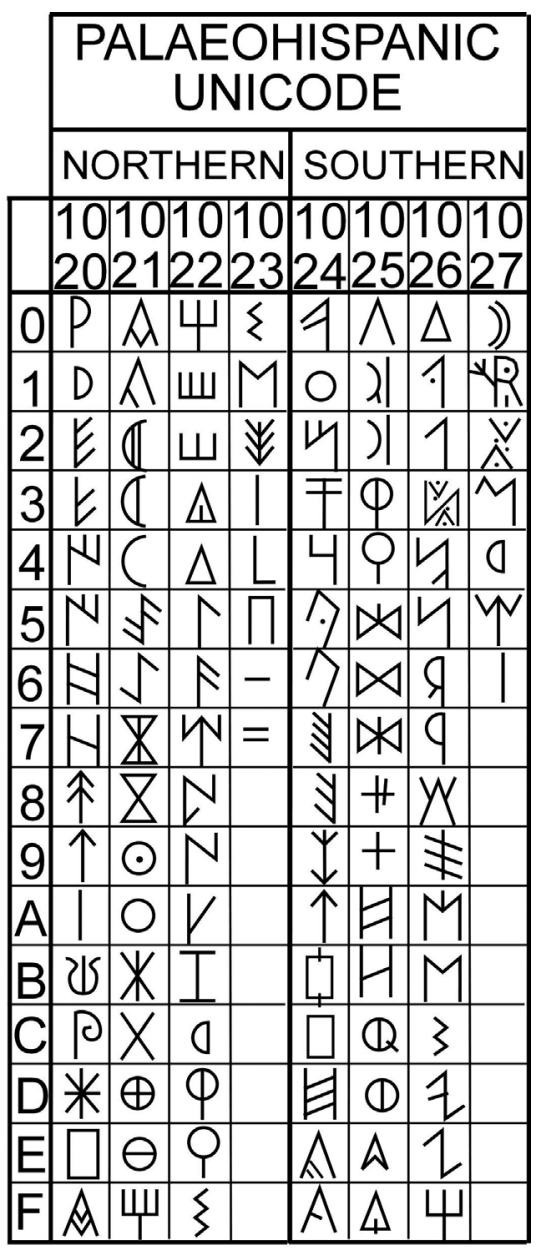




\section{$\begin{array}{llllllllllll}\mathbf{B} & \mathbf{I} & \mathbf{B} & \mathbf{L} & \mathbf{I} & \mathbf{O} & \mathbf{G} & \mathbf{R} & \mathbf{A} & \mathbf{F} & \mathbf{I} & \mathbf{A}\end{array}$}

Adiego 1993: I. J. Adiego, "Algunas reflexiones sobre el alfabeto de Espanca y las primitivas escrituras hispanas”, en: I. J. Adiego, J. Siles y J. Velaza, (eds.), Studia Palaeohispanica et Indogermanica J. Untermann ab amicis hispanicis oblata, Barcelona 1993, 11-22.

Burriel et al. 2011: J. M. Burriel, C. Mata, J. Ferrer i Jané, A.L. Ruiz, J. Velaza, M. A. Peiró, C. Roldán, S. Murcia y A. Doménech, "El plomo escrito del Tos Pelat (Moncada, Valencia)", PalHisp 11, 2011, 191-224.

Correa 1985: J. A. Correa, “Consideraciones sobre las inscripciones tartesias”, en: J. de Hoz (ed.), Actas del III Coloquio sobre Lenguas y Culturas Paleohispánicas (Lisboa, 5-8 noviembre 1980), Salamanca 1985, 377-385.

Correa 1987: J. A. Correa, "El signario tartesio", en: J. Gorrochategui, J. L. Melena y J. Santos (eds.), Studia Palaeohispanica. Actas del IV Coloquio sobre Lenguas y Culturas Paleohispánicas (Vitoria/Gasteiz, 6-10 mayo 1985), Vitoria 1987, 275-284.

Correa 1992a: J. A. Correa, "La epigrafia tartesia", Andalusien zwischen Vorgeschichte und Mittelalter. Forum Ibero-Americanum 7, Colonia 1992, 75-114.

Correa 1992b: J. A. Correa, "Representación gráfica de la oposición de sonoridad en las oclusivas ibéricas (semisilabario levantino)", AION 14, 1992, 253-292.

Correa 1993-1994: J. A. Correa, "La transcripción de las vibrantes de la escritura palaeohispánica", Archivo de Prehistoria Levantina 21, 1993-1994, 337-341.

Correa 1993: J. A. Correa, "El signario de Espanca (Castro Verde) y la escritura tartesia", en: J. Untermann y F. Villar (ed.), Lengua y cultura en la Hispania prerromana. Actas del V Coloquio sobre Lenguas y Culturas Prerromanas de la península ibérica (Colonia, 25-28 de noviembre de 1989), Salamanca 1993, 521-562.

Correa 1996: J. A. Correa, “La epigrafía del Sudoeste: estado de la cuestión”, en: F. Villar y J. D’Encarnação (eds.), La Hispania prerromana. Actas del VI Coloquio sobre Lenguas y Culturas Prerromanas de la península ibérica (Coimbra, 13-15 de octubre de 1994), Salamanca 1996, 65-75.

Correa 2005: J. A. Correa, “Escritura tartesia”, en: G. Carrasco y J. C. Oliva, (ed.), Escrituras y lenguas del Mediterráneo en la antigüedad, Cuenca 2005, 289-305.

Correa 2009: J. A. Correa, "Identidad, cultura y territorio en la Andalucía prerromana a través de la lengua y la epigrafía", en: F. Wulff Alonso y M. Álvarez Martí-Aguilar (ed.), Identidades, culturas y territorios en la Andalucía prerromana, Málaga 2009. 273-295.

Correa 2011: J. A. Correa, "La leyenda indígena de las monedas de Salacia y el grafito de Abul (Alcácer do Sal, Setúbal)", en: J. L. Cardoso y M. Almagro (eds.), Lucius Cornelius Bocchus, escritor lusitano da Idade da Prata, Lisboa-Madrid 2011, 103-112.

Correa y Zamora 2008: J. A. Correa y J. A. Zamora, "Un grafito tartesio hallado en el yacimiento del Castillo de Doña Blanca (Puerto de Sta. María, Cádiz)", PalHisp 8, 2008, 179-196.

Correia 1996: V. H. Correia, A epigrafia da Idade do Ferro do Sudoeste da península ibérica, Porto 1996. 
Correia 2014: V. H. Correia, "A escrita do sudoeste da península ibérica: velhos dados, novas teorias e a sua importância para o estudo das antigas culturas hispânicas", Portugalia Nova Série 35, 2014, 77-93.

De Hoz 1976: J. de Hoz, “La epigrafía prelatina meridional en Hispania”, en: F. Jordá, J. de Hoz y L. Michelena (eds.), Actas del I Coloquio sobre Lenguas y Culturas Prerromanas de la península ibérica (Salamanca, 27-31 mayo 1974), Salamanca 1976, 227-317.

De Hoz 1985: J. de Hoz, "El nuevo plomo inscrito de Castell y el problema de las oposiciones de sonoridad en ibérico", en Symbolae Ludouico Mitxelena septuagenario oblatae, Vitoria 1985, 443-453.

De Hoz 1986a: J. de Hoz, "Escritura fenicia y escrituras paleohispánicas”, Aula Orientalis 4, 1986, 73-84.

De Hoz 1986b: J. de Hoz, “La epigrafía celtibérica”, en: G. Fatás (ed.), Reunión sobre epigrafía hispánica de época romano-republicana (Zaragoza 1983), Zaragoza 1986, 43-102.

De Hoz 1989: J. de Hoz, El desarrollo de la escritura y las lenguas de la zona meridional", en: M. E. Aubet (ed.), Tartessos, Sabadell 1989, 523-587.

De Hoz 1993a: J. de Hoz, "La lengua y la escritura ibéricas y las lenguas de los íberos", en: J. Untermann y F. Villar (eds.), Lengua y cultura en la Hispania prerromana. Actas del V Coloquio sobre Lenguas y Culturas Prerromanas de la península ibérica (Colonia, 25-28 de noviembre de 1989), Salamanca 1993, 635-666.

De Hoz 1993b: J. de Hoz, "De la escritura meridional a la escritura ibérica levantina", en: F. Heidermanns, A. Rix y E. Seebold (eds.), Sprachen und Schriften des antiken Mittelmeerraums. Festschrift für Jürgen Untermann zum 65, Innsbruck 1993, 175-190.

De Hoz 1996: J. de Hoz, “El origen de las escrituras palaeohispánicas quince años después” en: F. Villar y J. D’Encarnação (eds.), La Hispania prerromana. Actas del VI Coloquio sobre Lenguas y Culturas Prerromanas de la península ibérica (Coimbra, 13-15 de octubre de 1994), Salamanca 1996, 171-206.

De Hoz 2005: J. de Hoz, "La recepción de la escritura en Hispania como fenómeno orientalizante", en: J. Jiménez Ávila y S. Celestino Pérez (ed.), El periodo orientalizante. Protohistoria del Mediterráneo occidental. Actas del III Simposio internacional de Arqueología de Mérida [Anejos de AespA 35], Madrid 2005, 363-380.

De Hoz 2007: J. de Hoz, "Cerámica y epigrafía paleohispánica de fecha prerromana”, AEspA 80, 2007, 29-42.

De Hoz 2010: J. de Hoz, Historia lingüistica de la península ibérica en la antigüedad. I. Preliminares y mundo meridional prerromano, Madrid 2010.

De Hoz 2011: J. de Hoz, Historia lingüística de la península ibérica en la Antigüedad. II. El mundo ibérico prerromano y la indoeuropeización, Madrid 2011.

De Hoz 2013: J. de Hoz, “La lingüística ibérica antes y después de Luis Michelena”, en: Koldo Mitxelena Katedraren III. Biltzarra, Vitoria 2013, 643-672.

De Hoz 2015: J. de Hoz, "La lengua ibérica en Jaén, desde el s. IV hasta las inscripciones de Piquía y las Atalayuelas", en: A. Ruiz y M. Molinos (eds.), Jaén, tierra ibera. 40 años de investigación y transferencia, Jaén 2015, 393-406.

Faria 1990-1991: A. M. de Faria, "Antropónimos em inscrições hispânicas meridionais", Portugalia Nova Serie 11-12, 1990-1991, 73-88.

Ferrer et al. 2016: J. Ferrer i Jané, D. Asensio y E. Pons, "Novetats epigràfiques ibèriques dels segles V-IV aC del Mas Castellar (Pontós, Alt Empordà)", Cypsela 20, 2016, 117-139.

Ferrer 2005: J. Ferrer i Jané, "Novetats sobre el sistema dual de diferenciació gràfica de les oclusives", PalHisp 5, 2005, 957-982. 
Joan Ferrer i Jané

Ferrer 2008: J. Ferrer i Jané, “Ibèric kaśtaun: un element característic del lèxic sobre torteres", Cypsela 17, 2008, 253-271.

Ferrer 2009: J. Ferrer i Jané, "El sistema de numerales ibérico: avances en su conocimiento", PalHisp 9, 2009, 451-479.

Ferrer 2010: J. Ferrer i Jané, "El sistema dual de l'escriptura ibèrica sud-oriental", Veleia 27, 2010, 69-113.

Ferrer 2013a: J. Ferrer i Jané, “Deux alphabets ibères duales rupestres de Cerdagne”, Sources 1, 2013, 9-18.

Ferrer 2013b: J. Ferrer i Jané, “Els sistemes duals de les escriptures ibèriques”, PalHisp 13, 2013, 445-459.

Ferrer 2014a: J. Ferrer i Jané, "Ibèric kutu i els abecedaris ibèrics”, Veleia 30, 2014, 227-259.

Ferrer 2014b: J. Ferrer i Jané, “Deux nouveaux alphabets ibères rupestres de Cerdagne”, Sources $2,2014,11-20$.

Ferrer 2015: J. Ferrer i Jané,, "Las dualidades secundarias de la escritura ibérica nororiental", ELEA 14, 2015, 309-364.

Ferrer 2016: J. Ferrer i Jané, “Una aproximació quantitativa a l'anàlisi de l'escriptura del sudoest”, PalHisp 16, 2016, 39-79.

Ferrer 2017: J. Ferrer i Jané, "El abecedario paleohispánico meridional del ostrakon de Villasviejas del Tamuja (Botija, Cáceres)", en: F. Hernández, A. M. Martín (eds.), Las Necrópolis de El Romazal y el Conjunto Arqueológico de Villasviejas del Tamuja (Cáceres), Madrid, 2017, 433-448.

Ferrer 2017a: J. Ferrer i Jané, "El origen dual de las escrituras paleohispánicas: un nuevo modelo genealógico", PalHisp 17, 2017, 55-94.

Ferrer 2018a: J. Ferrer i Jané, Lorigen i el desenvolupament de les escriptures paleohispàniques [Tesis doctoral de la Universidad de Barcelona], Barcelona 2018.

Ferrer 2018b: J. Ferrer i Jané, "El signo S65 de la escritura meridional: A propósito de la inscripción de la necrópolis de Piquía (Arjona, Jaén)”, ELEA, 2018, 139-180.

Ferrer 2019a: J. Ferrer i Jané, “Construint el panteó ibèric amb l'ajut de les inscripcions ibèriques rupestres", Ker 13, 2019, 42-57.

Ferrer 2019b: J. Ferrer i Jané, "A la recerca del trial: Les variants supercomplexes de les escriptures paleohispàniques", PalHisp 19, 2019, 27-53.

Ferrer e. p.a: J. Ferrer i Jané, "La escritura turdetana en el contexto de las escrituras paleohispánicas", en: N. Moncunill y M. Ramírez (ed.), Learning and Forgetting scripts, Vitoria, en prensa.

Ferrer e. p.b: J. Ferrer i Jané, "El sistema dual de la escritura celtibérica desde la perspectiva ibérica”, PalHisp 21, 2021, en prensa.

Ferrer et al. 2015: J. Ferrer I Jané, N. Moncunill y J. Velaza, “Towards a systematisation of Palaeohispanic scripts in Unicode: synthesising multiple transcription hypotheses into two consensus encodings", PalHisp 15, 2015, 13-55.

Ferrer y Moncunill 2019: J. Ferrer i Jané y N. Moncunill, "Palaeohispanic writing systems: classification, origin and development”, en: J. Velaza y A. G. Sinner (eds.), Palaeohispanic Languages and Epigraphies, Oxford 2019, 78-108.

Ferrer y Sánchez 2017: J. Ferrer i Jané y M. Sánchez, "L’enigma B’oide al descobert: kaśtaum i baikar en sengles inscripcions ibèriques sobre una tortera i un vaset de Vilademuls", Revista d'Arqueologia de Ponent 27, 2017, 221-236. 
García-Gelabert y Blázquez 1988: M. P. García-Gelabert y J. M. Blázquez, Excavaciones en la necrópolis ibérica del Estacar de Robarinas (S. IV a.C), Oxford 1988.

Gómez-Moreno 1922: M. Gómez-Moreno, “De epigrafía ibérica: El plomo de Alcoy”, Revista de Filología Española 9, 1922, 341-366.

Gómez-Moreno 1925: M. Gómez-Moreno, “Sobre los iberos y su lengua”, Homenaje a D. Ramón Menéndez Pidal III, 1925, 475-499.

Gómez-Moreno 1943: M. Gómez-Moreno, "La escritura ibérica y su lenguaje”, BRAH 112, 1943, 251-278.

Gómez-Moreno 1949: M. Gómez-Moreno, Misceláneas, Historia, Arte, Arqueología, Madrid 1949.

Gómez-Moreno 1961: M. Gómez-Moreno, "La escritura bástulo-turdetana (primitiva hispánica)", Revista de Archivos Bibliotecas y Museos 69/2, 1961, 879-948.

Guerra 2002: A. Guerra, "Novos monumentos epigrafados com escrita do Sudoeste da vertente setentrional da Serra do Caldeirão", Revista Portuguesa de Arqueologia 5/2, 2002, 219-231.

Guerra 2009: A. Guerra, "Novidades no âmbito da epigrafia pré-romana do Sudoeste hispânico", PalHisp 9, 2009, 323-338.

Jordán 2005: C. Jordán, “Sistema dual de escritura en celtibérico?” PalHisp 5, 2005, 1013-1030.

Jordán 2007: C. Jordán, "Estudios sobre el Sistema Dual de Escritura en Epigrafia no Monetal Celtibérica”, PalHisp 7, 2007 101-142.

Jordán 2019: C. Jordán, Lengua y Epigrafía celtibéricas, Zaragoza 2019.

Maluquer 1968: J. Maluquer, Epigrafía prelatina de la península ibérica, Barcelona 1968.

Mederos y Ruiz 2001: A. Mederos y L. A. Ruiz, "Los inicios de la escritura en la península ibérica. Grafitos en cerámicas del Bronce Final III y fenicias", Complutum 12, 2001, 97-112.

MLH III: J. Untermann, Monumenta Linguarum Hispanicarum. III Die iberischen nschriften aus Spanien, Wiesbaden 1990.

MLH IV: J. Untermann, Monumenta Linguarum Hispanicarum IV Die tartessischen, keltiberischen und lusitanischen Inschriften, Wiesbaden.

Rodríguez Ramos 1997: J. Rodríguez Ramos, "Sobre el origen de la escritura celtibérica", Kalathos 16, 1997, 189-197.

Rodríguez Ramos 2000: J. Rodríguez Ramos, "La lectura de las inscripciones sudlusitanotartesias", Faventia 22/1, 2000, 21-48.

Rodríguez Ramos 2001: J. Rodríguez Ramos, "Signos de lectura problemática en la escritura ibérica", AEspA 74, 2001, 281-290.

Rodríguez Ramos 2002: J. Rodríguez Ramos, "Las inscripciones sudlusitano-tartesias, su función, lengua y contexto socio-económico", Complutum 13, 2002, 85-95.

Rodríguez Ramos 2002a: J. Rodríguez Ramos, "La escritura ibérica meridional", Zephyrus 55, 2002, 231-245.

Rodríguez Ramos 2004: J. Rodríguez Ramos, Análisis de epigrafía íbera [Anejos de Veleia, Series Minor 12], 2004, Vitoria 2004.

Rodríguez Ramos 2005: J. Rodríguez Ramos, “Introducció a l’estudi de les inscripcions ibèriques", Revista de la Fundació Privada Catalana per l'Arqueologia ibèrica 1, 2005, 13-144.

Rodríguez Ramos 2006: J. Rodríguez Ramos, “Algunos comentarios a propósito de la inscripción ibérica de Los Allozos”, Arse 40, 2006, 2945.

Rodríguez Ramos 2015: J. Rodríguez Ramos, "De nuevo sobre la lectura de la escritura monumental tartesia o sudlusitana", Veleia 32, 2015, 125-150.

Schmoll 1961: U. Schmoll, Die sudlusitanischen Inschriften, Wiesbaden 1961. 
Joan Ferrer i Jané

Simón 2013: I. Simón, “El final de las escrituras paleohispánicas”, PalHisp 13, 2013, 167-186.

Toscano y Correa 2014: C. Toscano y J. A. Correa, "Grafitos tartesios hallados en Niebla (Huelva) y su contexto arqueológico", Onoba 2, 2014, 45-54.

Valério 2008: M. Valério, "Origin and development of the Palaeohispanic scripts: the orthography and phonology of the Southwestern alphabet", Revista Portuguesa de Arqueologia 11/2, 2008, 107-128.

Valério 2016: M. Valério, "Reflexões sobre a origem e formação da escrita paleo-hispânica do Sudoeste e o seu lugar na história dos sistemas de escrita", PalHisp 16, 2016, 15-151.

Velaza e. p.: J. Velaza "Inscripción celtibérica sobre falera procedente de Armuña de Tajuña (GU)", en prensa. 